This manuscript is a preprint and will be shortly submitted for publication to a scientific journal. As a function of the peer-reviewing process that this manuscript will undergo, its structure and content may change.

If accepted, the final version of this manuscript will be available via the 'Peer-reviewed Publication DOI' link on the right-hand side of this webpage. Please feel free to contact any of the authors; we welcome feedback. 


\title{
Earthquake-triggered landslide susceptibility in Italy by means of Artificial Neural Network
}

\author{
Gabriele Amato $^{1 *}$, Matteo Fiorucci², Salvatore Martino ${ }^{2}$, Luigi Lombardo ${ }^{3}$, \\ Lorenzo Palombi ${ }^{1}$
}

\footnotetext{
1 "Nello Carrara" Applied Physics Institute - National Research Council of Italy (IFAC-CNR), Via Madonna del Piano 10, 50019 Sesto Fiorentino (FI), Italy

2 "Sapienza" University of Rome, Department of Earth Sciences and Research Centre for Geological Risks (CERI), P.le A. Moro 5, 00185, Rome, Italy

${ }^{3}$ University of Twente, Faculty of Geo-Information Science and Earth Observation (ITC), PO Box 217 , Enschede, AE 7500, Netherlands
} 


\section{Contents}

1 Introduction $\quad 3$

2 Background $\quad 3$

3 Material and methods $\quad 8$

3.1 Italian morphotectonic settings . . . . . . . . . . . . . . . . 8

3.2 CEDIT catalogue . . . . . . . . . . . . . . . . . . 8

4 Model building strategy 13

4.1 Mapping unit . . . . . . . . . . . . . . . . . . . . . 13

4.2 Predictor variables . . . . . . . . . . . . . . . . . . . . . . 14

4.2.1 Geothematic predictors . . . . . . . . . . . . . 17

4.2.2 Seismic predictors: distance to seismogenic features . . . . . . . . . . 17

4.2 .3 Terrain predictors . . . . . . . . . . . . . . . . . 20

4.2.4 Anthropic predictors: distance to roads . . . . . . . . . . . . . . . 21

4.2.5 Hydrological predictors: distance to watercourses . . . . . . . . . . . 22

4.3 Artificial Neural Network . . . . . . . . . . . . . . . . . . . . . . . 22

4.4 Performance assessment: validation routines . . . . . . . . . . . . . . 23

5 Results $\quad 25$

5.1 Susceptibility mapping . . . . . . . . . . . . . . . . . . 26

5.2 Predictors' importance . . . . . . . . . . . . . . . . . . . 30

$\begin{array}{lll}6 & \text { Discussions } & 37\end{array}$

6.1 Supporting arguments . . . . . . . . . . . . . . . . 37

6.1.1 Quality and completeness ................. 37

6.1.2 ANN performance overview . . . . . . . . . . . . . . . 39

6.1.3 EQtLs Susceptibility patterns . . . . . . . . . . . . . . . 39

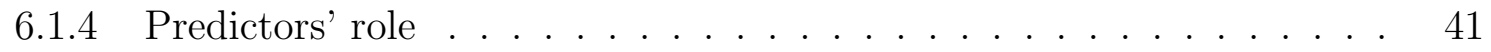

6.2 Opposing arguments . . . . . . . . . . . . . . . . . . . . 43

6.2.1 Validation routine through the Check data . . . . . . . . . . . . 43

6.2.2 Predictors associated to tectonic elements . . . . . . . . . . . . . 44

6.2.3 Model interpretability . . . . . . . . . . . . . . . 44

7 Concluding remarks $\quad 45$ 


\section{Introduction}

In this study we performed a susceptibility analysis of earthquake triggered landslides for the whole Italian territory by implementing an Artificial Neural Network (ANN; Hassoun et al., 1995) approach. Slope units have been adopted as mapping units (Alviolicor et al., 2020). The input landslides inventory used to train the network has been accessed via the Italian Catalogue of Earthquake-Induced Ground Failures (CEDIT) (Fortunato et al., 2012; Martino et al., 2014; Caprari et al., 2018), which collects ground effects, among which landslides, caused by earthquakes occurred over the whole Italian territory from the XII century to present days. As far as the authors know, this represents the first study dealing with earthquakes-triggered landslide (EQtLs) susceptibility for the whole Italian territory. To clearly evaluate and present the achieved results, we quantified the ANN classification performances through commonly adopted metrics and we generated the first Italian EQtLS susceptibility map. Besides, we investigated the importance of the predictors performing a Permutation Feature Importance (PFI) of single predictors and explored how the classification performance varies selecting all the possible combinations among predictors groups (i.e. terrain, seismic, geothematic, hydrological and anthropic predictors). Ultimately, we checked the obtained susceptibility map for every Italian administrative region, by using an additional landslide dataset, which was not included during the ANN training phase. The resulting percentage of unstable territory for every Italian region has been computed to highlight priorities in land management practices at more local scales other than the national one.

The present manuscript is organized as follows: Section 2 provides a literature review in the context of EQtLS and the historical evolution of models able to predict these phenomena. Section 3 provides the required information on the landslide data used in this study, the selected mapping unit, the predictor set and the modeling framework. Section 5 presents the results which are then discussed in depth and from an holistic perspective in Section 6. Section 7 concludes the manuscript and opens towards future possible improvements.

\section{Background}

The concept of landslide susceptibility defines the expectation of where landslides may occur in a given landscape, thus providing information on the spatial component of the landslide hazard definition (Varnes and the IAEG Commission on Landslides and Other MassMovements, 1984; Guzzetti et al., 1999; Lombardo et al., 2020a). The numerical expression of a landslide susceptibility corresponds to the probability of landslide occurrences within a given mapping unit (Lima et al., 2017; Broeckx et al., 2018; Lombardo and Mai, 2018). This definition has consequences on how the probabilities are generated, either via physically(e.g., Bout et al., 2018) or statistically- (e.g., Reichenbach et al., 2018) based methods. For the latter case, to express how prone a given landscape is to initiate slope failures over 
space, the component related to the trigger is not featured as a predictor and this usually appears as part of landslide hazard studies. The few exceptions to this rule consist of susceptibility assessments made in near-real-time in case of landslides triggered by transitory events, i.e. intense rainfall (Kirschbaum et al., 2012) or earthquake (Nowicki Jessee et al., 2018; Lombardo and Tanyas, 2020). Among the landslides triggered by transitory events, the earthquake-triggered ones are generally responsible for severe damages and losses, as demonstrated by the last decadal records, when more than $50 \%$ of the total worldwide losses due to landslides are associated to co-seismic slope failures (Petley, 2012). In this context, the recent strong earthquakes in Sumatra (2004, $\mathrm{M}_{w}$ 9.1), eastern Sichuan (China 2008, $\mathrm{M}_{w}$ 7.9) and Tohoku (Japan 2011, $\mathrm{M}_{w}$ 9.0) have confirmed that earthquake-triggered ground effects (e.g., tsunamis, landslides and liquefaction) can be responsible for major damage and losses. As reported by Bird and Bommer (2004), the largest damage caused by earthquakes are often related to landslide events. Furthermore, several historical disasters confirmed the severity of EQtLs. For instance, the Las Colinas landslide, triggered by the January $13^{\text {th }}$ $2001 \mathrm{M}_{w} 7.6 \mathrm{El}$ Salvador earthquake, caused approximately 600 victims (Evans and Bent, 2004) while the Scilla rock avalanche, triggered by the February $6^{\text {th }} 1783$ earthquake in Southern Italy (Bozzano et al., 2011; Mazzanti and Bozzano, 2011; Martino, 2017), killed approximately 1500 people in a cascading effect that led to a $16 \mathrm{~m}$ high tsunami wave.

Taking aside the potential casualties, another source of potential losses in post-earthquake scenarios is represented by landslides affecting transportation routes and inhibiting recovery and safety operations during emergency phases (Martino et al., 2019). More generally, the risk related to the earthquake shaking can be also significantly increased by additional earthquake-triggered effects. These can involve localities distant up to tens or hundreds of kilometres from the earthquake epicentre (Keefer, 1984; Rodriguez et al., 1999; Delgado et al., 2011; Jibson and Harp, 2012). During the last decades, they have been confirmed by several authors reporting on ground failures triggered by earthquakes (Bommer and Rodriguez, 2002; Sepúlveda et al., 2005; Porfido et al., 2007; Tosatti et al., 2008; Gorum et al., 2011; Tang et al., 2011; Alfaro et al., 2012; Martino et al., 2020a, among others). To preemptively reduce the risk associated with these processes, predictive models have been proposed to estimate the distribution of earthquake-triggered ground effects scenarios (Sassa, 1996; Jibson et al., 2000; Prestininzi and Romeo, 2000; Romeo, 2000; Jibson, 2007; Hsieh and Lee, 2011, among others) representative of a uniform hazard distribution or seismic shaking scenarios. Out of several available options proposed to preemptively estimate earthquake-triggered effects, the proposed approaches essentially boil down to two types: physically-based approaches (Van Westen et al., 2006) and the statistically-based ones (Guzzetti et al., 2005). The first type of approaches implies that slope stability analyses are performed to quantify safety factors (Martino, 2016) and/or the expected seismically induced displacements of the landslide masses. Slope stability analyses under seismic stress are traditionally performed by pseudostatic approaches that assume a constant equivalent seismic action, expressed by an horizontal pseudostatic seismic coefficient $\left(\mathrm{k}_{x}\right)$. This is applied to the landslide mass, 
in addition to the gravity force. The SF is computed as the ratio between the available strength along the sliding surface and the acting forces. The force equilibrium analysis demonstrates that the pseudostatic force related to the $\mathrm{k}_{x}$ is responsible for the reduction of the available strength and for the increase of the forces acting along the sliding surface. The critical threshold acceleration $\left(\mathrm{k}_{c}\right)$ coincides with the value at which SF becomes equal to 1 . An alternative to the pseudostatic solution for slope stability analysis under seismic action is provided by unconventional pseudostatic analysis that reduce the restrictions imposed by traditional approaches by considering distributions of $\mathrm{k}_{x}$ within the landslide mass according to sine waves functions (Delgado et al., 2015; Lenti et al., 2017). In this context, the landslide mass is partitioned into slices (i.e. delimited by vertical boundaries) and different $\mathrm{k}_{x}$ values are applied to each slice based on the spatial distribution of the horizontal acceleration values associated to the sine wave function (Lenti et al., 2017). Furthermore, on the basis of the Newmark's method, co-seismic displacements can be more extensively computed at a basin-to-regional scale. This can be achieved by fixing critical acceleration thresholds $\left(\mathrm{k}_{c}\right)$ and considering distribution of ground-shaking parameters (i.e., PGA namely, peak ground acceleration, or Arias intensity) derived from specific thematic maps (Jibson et al., 2000), usually managed via Geographic Information Systems (GIS). While $\mathrm{k}_{c}$ is derived from a combination of slope geometry and strength properties of the outcropping lithologies, PGAvalues are attributed to each grid node by applying a ground-motion according to attenuation law, in case of a specific seismic scenario or in case uniform hazard maps for multi-hazard risk analysis. The reliability of this approach for EQtLs scenarios at a regional scale was initially tested in California (Jibson et al., 1998; Miles and Ho, 1999; Jibson et al., 2000; Jibson, 2007) taking into account well-documented seismically induced landslide effects due to the Northridge earthquake (January $17^{\text {th }} 1994$ ). Since then, the probabilistic seismic landslide hazard-mapping based on the computation of Newmark's co-seismic displacements has been applied at a regional scale by many researchers in other areas and case studies (Capolongo et al., 2002; Saygili and Rathje, 2009; Wang and Lin, 2010). The most simplified assumptions of the Newmark's approach consist of neglecting the internal deformations produced during the seismic shaking, which are responsible for amplification of the seismic motion. To address this approximation, coupled or decoupled solutions have been proposed (Makdisi and Seed, 1978; Rathje et al., 1998; Rathje and Bray, 2000). These account for fully nonlinear soil properties' behaviour during the seismic shaking (Rathje and Bray, 2000) and they also consider the probabilistic variation of seismic input properties (Bray and Travasarou, 2007). Based on more sophisticated computational approaches, which are comprehensive of different landslide mechanisms and methods for slope stability analysis, probability maps of expected Newmark's displacements can be obtained at a regional scale through the recently proposed PARSIFAL (Probabilistic Approach to pRovide Scenarios of earthquake-Induced slope FAiLures) approach (Esposito et al., 2016; Martino et al., 2018, 2019). PARSIFAL considers both landslide susceptibility maps and landslide inventories for detecting slope areas prone to landslides, to compute probability of EQtLs occurrence, based on distributions 
of Newmark's displacement values related to an input subset.

As regards the statistically-based counterpart, whether one models rainfall- or earthquaketriggered landslides, the general framework is quite similar when data-driven (statistical and machine learning) models are used. In both cases, a mapping unit is typically chosen between grid-cells and slope-units and a dichotomous status expressing the absence or presence of landslides (or 0/1) is assigned. In a subsequent step, the binary status is then fitted to a set of predictors chosen to represent predisposing factors of slope instability and the outcome of the modeling procedure is a probability (Amato et al., 2019). However, the algorithmic architecture one chooses to implement has notable repercussions on the performance each model provides. For instance, simple bivariate statistical models provide quite straightforward interpretation of the functional relations existing between factors and landslides (e.g., Weight of Evidence; Bonham-Carter, 1989; Van Westen, 2002; Martino et al., 2019). But, this is achieved at the expense of the statistical rigor (the model does not assume any underlying probability distribution nor the interaction among explanatory variables) and performances, which are usually superseded by more complex statistical tools. For instance, multivariate statistical routines assume that landslides are distributed over space according to the Bernoulli probability distribution (Lombardo et al., 2019). And, they allow to model linear relations (in case of Generalized Linear Models; Ayalew and Yamagishi, 2005; Castro Camilo et al., 2017) or a combination of linear and nonlinear relations (in case of Generalized Additive Models; Brenning, 2008; Goetz et al., 2011) between predisposing factors and landslides occurrences. These models offer excellent performance while keeping a clear interpretability at each step and for each model component (Lombardo et al., 2014; Frattini et al., 2010). Ultimately, machine learning methods provide equally and often even higher performance than the other two approaches mentioned above, this time though at the expense of the interpretability of each step, which has commonly earned them the label of "black boxes" (Korup and Stolle, 2014; Goetz et al., 2015). The reason behind this characteristic is due to the fact that machine learning algorithms are often based on the combination of highly nonlinear functions which are difficult to be individually and multivariately traced as the model evolves converging to the best solution (Liu et al., 2014; Zhou et al., 2016, 2018). Because of the high performance provided, machine learning has become mainstream in many scientific applications and landslide science has also seen the number of such applications rise in recent years (Marjanović et al., 2011; Huang et al., 2017; Zhu et al., 2017). For instance, algorithms belonging to the family of decision trees have become quite common, and several examples can be found from simpler Classification And Regression Trees (e.g., Althuwaynee et al., 2014), to more complex Random Forests (e.g., Lagomarsino et al., 2017) and Stochastic Gradient Boosted Trees (e.g., Lombardo et al., 2015). Similarly, Artificial Neural Networks (e.g., Ermini et al., 2005; Gomez and Kavzoglu, 2005) and their more recent convolutional extensions (e.g., Wang et al., 2019) have equally demonstrated to be a valid tool for landslide susceptibility assessment. Neural networks are characterised by the possibility of modelling the relationship between independent and dependent variables in a complex non-linear way 
and are by nature prone to overparameterization of the model itself. These aspects lead to both advantages and disadvantages with respect to more classical methodologies. The advantages are mainly to be found in the ability to model complex relations when these are not known a priori and in the fact that, thanks to overparameterization, they are very little sensitive to problems of collinearity (De Veaux and Ungar, 1994) between independent variables. This typically ensures a greater robustness of the predictive performances (Garg and Tai, 2012). To better clarify this point, Kutner et al. (2005) stated that "the fact that some or all predictor variables are correlated among themselves does not, in general, inhibit our ability to obtain a good fit nor does it tend to affect inferences about mean responses or predictions of new observations, provided these inferences are made within the region of observations". However, due to overparameterization, they are not typically used for a model interpretation but mainly for predictive purposes. Thus, ANNs approaches are particularly suitable for big data. And, expert knowledge is not required to generate reproducible results (Taalab et al., 2018). As a consequence, a growing number of landslide susceptibility models rely on $\overline{\mathrm{ANN}}$. The most common procedure is to train an ANN over a landslide inventory while featuring a set of input factors assumed to promote failures. As a result, a probability value of landslide susceptibility per mapping unit is returned (Can et al., 2019).

Both physically- and statistically- based approaches typically require high-resolution datasets, i.e. characterized by a suitable completeness and a good to very good quality of technical parameters, that can support the validation and guarantee a high reliability of the quantitative outputs. In this regard, the spatial scale of the case study represents a fundamental feature as it can modify the input resolution and, as a consequence, the resolution of the output itself. Therefore, the spatial scale influences the operational use of the estimated scenarios. A slope to catchment scale assessment can be suitable for seismic microzonation studies and its value can be maximized within local administrations to design engineering interventions or propose zoning plans at a municipality scale. Conversely, a regional to national scale assessment has implications on how decision makers prioritize interventions for seismic (and associated cascading effects) risk management and mitigation. Thus its value is maximized at governmental levels to allocate resources knowing which parts of the territory are more vulnerable. Examples of earthquakes-triggered landslide susceptibility analysis are numerous and some already adopted ANN approaches (Lee and Evangelista, 2006; Tian et al., 2019). Most of them perform analysis at a regional scale (Song et al., 2012; Umar et al., 2014; Zhou and Fang, 2015) using input landslide inventories that are limited in time and space to single earthquakes (Tanyaş et al., 2017; Shrestha and Kang, 2019; Tanyaş and Lombardo, 2020). 


\section{Material and methods}

\subsection{Italian morphotectonic settings}

Italy is the European country mostly affected by landslides (Herrera et al., 2018), with over 620,000 landslides recorded in the framework of the IFFI dataset, the most complete and detailed landslides inventory existing in Italy (Trigila et al., 2013). The main triggering factors for landslides in Italy are intense rainfalls and earthquakes. And in recent years, anthropogenic factors such as road cuts have assumed to also play an increasing role. Since 1999 until December 2019, more than 3000 interventions for landslide risk mitigation were financed by the Italian institutions, for a total of almost two billions of Euros. It has been verified that almost $70 \%$ of the proposed interventions fall within or close to areas classified with a high landslide hazard (link here), making the classification of the territory of high relevance to establish the remediation funding priorities. Italy is also characterized by an active geodynamics related to the geological evolution of the two major mountain chains, i.e. the Alps in the north and the Apennines throughout the peninsula, as testified by the distribution of earthquakes and volcanic activity. More specifically, the Alps' chain shows a double-verging growth, involving the exhumation of metamorphic rocks. Conversely, the Apennines chain consists of a single-east-verging belt, mostly characterized by thin-skinned tectonics. As a consequence, earthquakes show prevalent compressional focal mechanisms at the fronts of the two chains and extensional mechanisms along the Apennines backbone (Carminati et al., 2010). The highest magnitude seismic events, with peak ground acceleration (PGA) values higher than $0.225 \mathrm{~g}$ and a return time of 475 years, are expected in the central-southern Apennines, Calabria region (on the southwest of the Italian peninsula), in the southeastern part of Sicily island and in the north-eastearn sector of the Alps chain. Medium to low seismic acceleration values (PGA up to $0.225 \mathrm{~g}$ ) are expected with a return time of 475 years along the entire Alpine Arch, along the entire western Italian coast and the peri-Adriatic regions (eastern Italian coast). Ultimately, the Sardinia island is the only sector with very low seismic hazard (link here). The national probabilistic model of seismic hazard in Italy has been generated also thanks to the continuously ongoing collection and study of the Italian seismogenic sources inventoried in the Database of Italian Seismogenic Sources (DISS) catalogue (link here).

\subsection{CEDIT catalogue}

The EQtLs susceptibility model we built in this study is based on data collected in the CEDIT (Italian acronym of "Italian database of earthquake-triggered ground failures") catalogue (Martino et al., 2014). This catalogue contains records of several ground effects triggered by earthquakes within the Italian territory from 1117 d.C. to August $16^{\text {th }}$ 2018, when the $\mathrm{M}_{w} 5.1$ Montecilfone earthquake occurred in the Molise region (Prestininzi and Romeo, 2000; Fortunato et al., 2012; Martino et al., 2019, 2020a). The latest release of the catalogue 
(Caprari et al., 2018) is available online at (link here), and consists of a relational geodatabase in which each earthquake is associated with all the multiple ground-failure effects induced by it. For earthquakes occurred before 1980, the information about the induced ground failures are mainly taken by historical documents and literature, while the ground effects induced by more recent events have been surveyed directly on the field by the CERI (Research Centre for the Geological Risks of Sapienza University of Roma) working group (see Martino et al., 2017, for more details on the standard cataloging procedure). The collected earthquake-triggered ground effects are grouped into 5 macro-categories: i) landslides; ii) ground-cracks; iii) liquefactions; iv) surface faulting; and $v$ ) ground changes such as subsidence or sinkholes. These main categories are further divided into sub-categories, reporting the type of effect, such as (e.g.) the landslide kinematic type (according to Varnes and the IAEG Commission on Landslides and Other Mass-Movements, 1984).

The updated version of the CEDIT contains data related to 173 earthquakes, spatially distributed over more than 1575 Italian localities, for a total of 3989 seismic-induced effects, out of which 2222 are landslides (equal to 56\%), 903 ground-cracks (23\%), 486 liquefaction phenomena (12\%), 183 surface faulting (4\%) and 195 phenomena of permanent ground level deformation (5\%). The main information associated with each earthquake-triggered ground effect are the geographical coordinates, the type of effect, the epicentral distance, the macroseismic intensity (MCS scale; Sieberg, 1930) attributed to the effect site and the main lithology involved. More specifically, regarding the geolocalisation of the effects, 5 different classes of georeferencing exist in accordance with the administrative hierarchy of Italian territories. With this aim, the CEDIT also features an error estimation assigned to each ground effect location according to the following ranking scheme, from the most to the least accurate (Martino et al., 2014):

- class 5: site coordinates (high quality location from historical documents or GPS measurement) associated with no error or negligible;

- class 4: locality coordinates (area extent of square kilometres) associated with an average error of $1 \mathrm{~km}$;

- class 3: main town coordinates (area extent of tens of square kilometres) associated with an average error of $3 \mathrm{~km}$;

- class 2: municipality coordinates (area extent of hundreds of square kilometres) associated with an average error of $10 \mathrm{~km}$;

- class 1: region coordinates (area extent of thousands of square kilometres) associated with an average error of $30 \mathrm{~km}$.

In general, the older the effects, the greater are the errors in geographical location. However, the revision of historical sources has led to the attribution of high georeferencing classes also to effects triggered by earthquakes occurred before the use of GPS became 
a

common practice. The latest revision of the CEDIT catalogue was carried out in 2020 for the Reggio and Messina 1908 earthquake, based on the data reported in Comerci et al. (2015), and led to attribution of class 5 to 87 effects that previously belonged to minor classes (Martino et al., 2020c). With the aim to provide a reliable geolocalized landslide dataset, the susceptibility analysis here presented only featured EQtLs extracted from the CEDIT catalogue and they were split in two different subsets (Fig.1):

1. An "Input dataset" containing 1545 landslides, all belonging to the georeferencing class 5. These were induced by the earthquakes that occurred in Italy from 1908 to 2018 .

2. A "Check dataset" containing 465 landslides with georeferencing classes ranging from 1 to 4 , induced by all the earthquakes contained in the CEDIT catalogue, and 54 landslides belonging to the georeferencing class 5 , induced by earthquakes that occurred in Italy before 1908 .

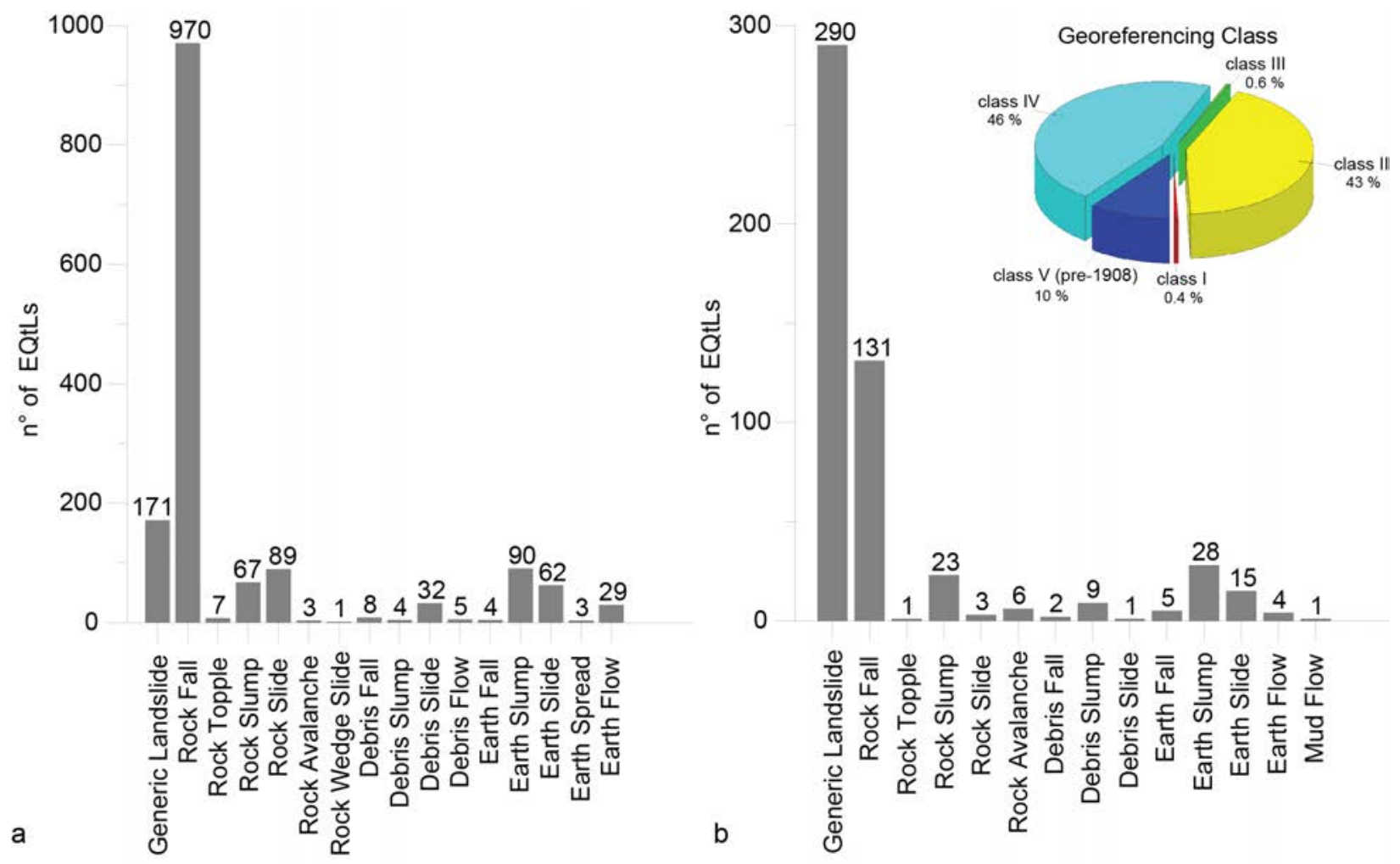

Figure 1: Bar chart showing the distribution of the type of EQtLs for Input dataset (a) and for Check dataset (b), together with the georeferencing class distribution for the Check dataset only (b).

We used the Input dataset for the training and cross-validation-test cycles of the neural network, whereas we used the Check dataset to perform a-posteriori and independent verification of the EQtLs susceptibility map of Italy. The spatial distribution of the two here 
considered datasets (i.e., earthquake-induced landslides for Input and Check) are shown in Figure 2.

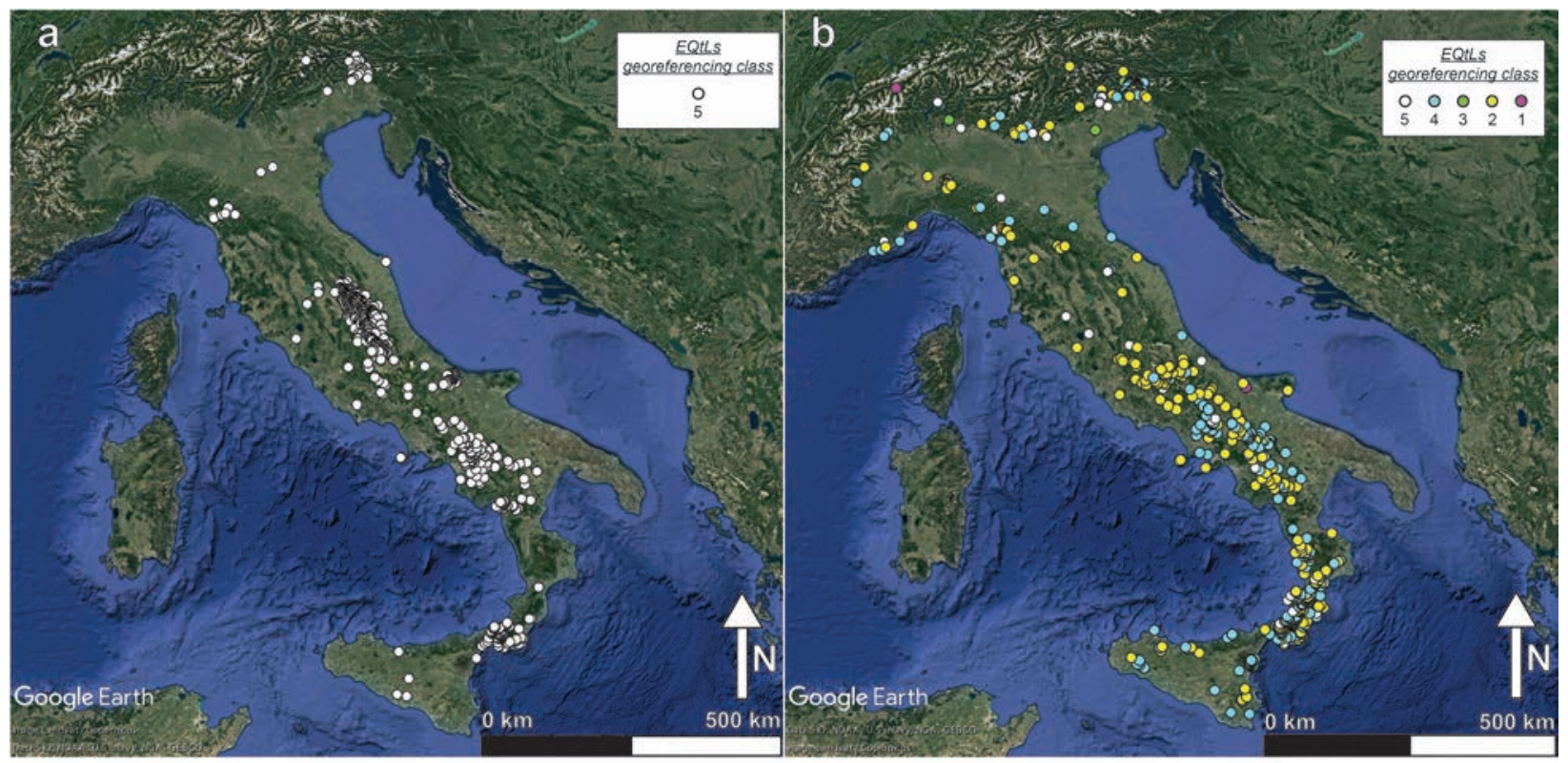

Figure 2: a) Spatial distribution of EQtLs belonging to Input dataset and b) of EQtLs belonging to Check dataset, coloured on the basis of their georeferencing class.

The epicentral distance is an important feature to be collected when compiling a dataset of earthquake-triggered ground effects. The Keefer curve (Keefer, 1984) and its upgrade (Rodriguez et al., 1999) is an experimental curve that defines the maximum expected epicentral distance of a landslide induced by an earthquake of a given magnitude and is taken as reference to evaluate the reliability of an EQtLs dataset. Martino et al. (2014) defined a similar curve for Italy (the CEDIT curve) calibrated taking into account rock fall and disrupted landslides induced by earthquakes occurred starting from 1908 (Reggio and Messina earthquake) until 2012 (Emilia earthquake) and geolocalised with greater precision than those further away in time. The maximum distances of earthquake-induced effects surveyed with the use of GPS immediately after the seismic sequence of central Italy in 2016-2017 (Martino et al., 2019) and after the Montecilfone earthquake in 2018 (Martino et al., 2020a) well respected the maximum epicentral distance for disrupted landslides defined for Italy (CEDIT curve). In this way, the Input dataset respects the CEDIT curve and can thus be considered as a reliable dataset to train the neural network (see Figure 3). 


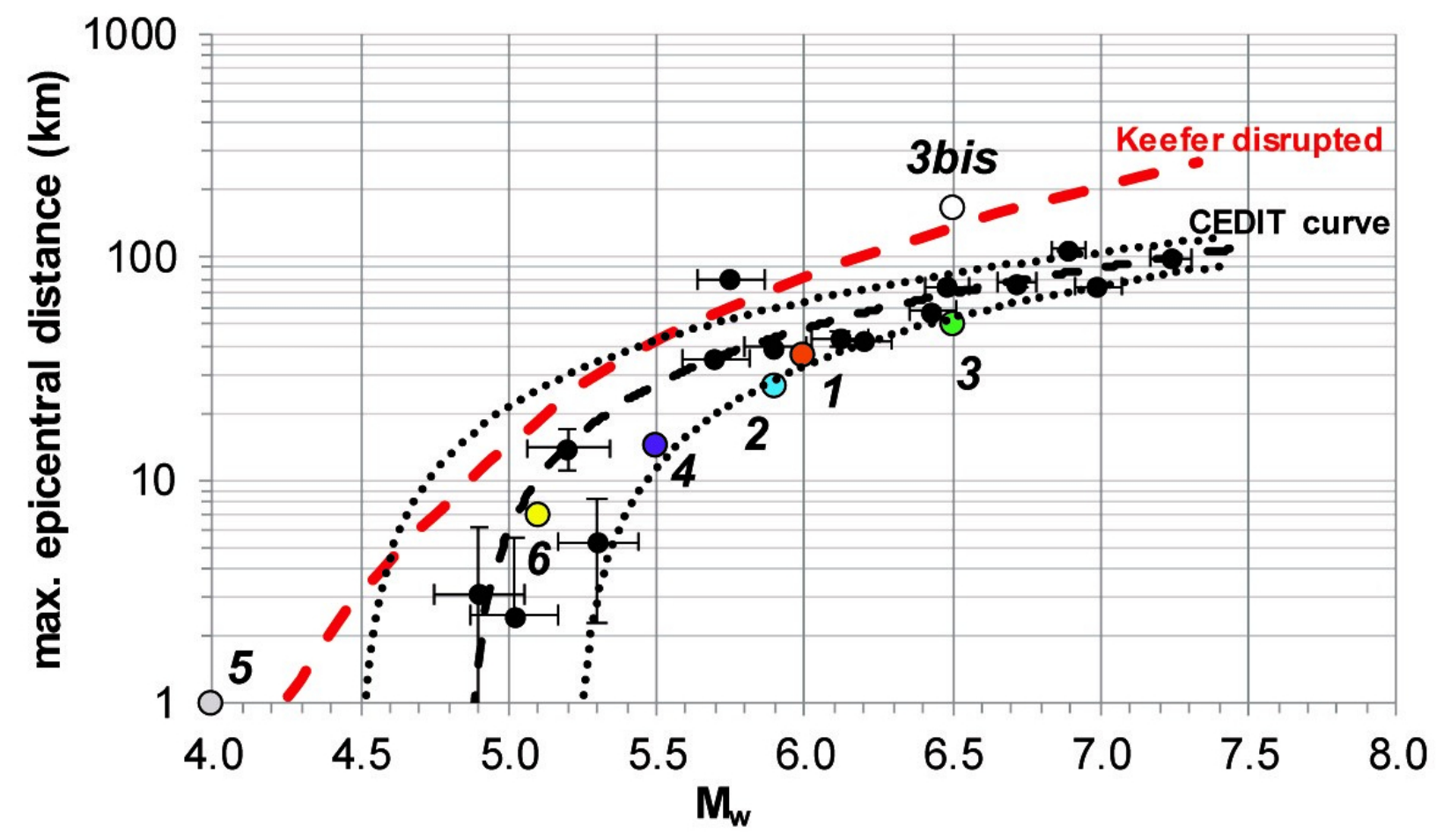

Figure 3: Magnitude-distance relationships for landslides in time periods 1908-2012 (black circles) compared to Keefer (1984) upper bound for disrupted landslides (red dashed line). Black dotted lines represent the standard error of the best-fit line for Italy (black dashed line) based on the CEDIT catalogue. Further effect triggered by the most recent earthquakes: 1 - 2016 Amatrice earthquake (orange circle); 2 - 2016 Castelsantangelo sul Nera earthquake (blue circle); 3 - 2016 Norcia earthquake (green circle); 3bis- 2016 Norcia earthquake outlier (white circle); 4 - 2017 Capitignano earthquake (purple circle); 5 - 2017 Ischia earthquake (grey circle); 6 - 2018 Montecilfone earthquake (yellow circle); (modified from Martino et al., 2014). 


\section{Model building strategy}

\subsection{Mapping unit}

A mapping unit in landslide science is considered to be a geographical object upon which the landscape is partitioned (Carrara, 1988). Such units constitute the spatial domain used to aggregate terrain and thematic properties as well as the units for which a given susceptibility model estimates the probability of landslide occurrence (Carrara, 1983). The vast majority of the landslide susceptibility literature is based on regular mapping units shaped as a squared (e.g., Jibson et al., 2000; Steger et al., 2020) or hexagonal (Avolio et al., 2013; Lupiano et al., 2018) lattice. However, when it comes to statistically-based applications, the way these units are used is generally flawed for a few reasons. These have been extensively described in Reichenbach et al. (2018) and we direct the reader to this article for more details. Nevertheless, we will briefly summarize those reasons below. First, the size of the grid is almost constantly chosen with a resolution that simply matches the resolution of the available Digital Elevation Model (DEM) rather than following a scientifically sound criterion. The choice is chiefly controlled by the availability of data, which is unrelated to the actual landslide initiation process. In other words, a grid-cell-based partition of the landscape is independent from the failure mechanisms because landslides are not spatially continuous phenomena such as temperature or rainfall patterns for instance. Conversely, landslides are discrete geomorphological processes that occur on slopes rather than a gridcell. Furthermore, the choice of the grid-cell size is chosen independently of the landslide type (Cama et al., 2016), which intuitively should involve a much larger unstable area for deepseated landslides (thus requiring a larger theoretical grid-cell) and a much more localized triggering area for shallow slope failures (thus requiring a smaller theoretical grid-cell). The main weakness of this mapping unit is also its translation into an operational tool. In fact, when we look at a landscape we do not see grids but rather slopes and this is reflected especially in the output of a grid-cell-based susceptibility model. In fact, whenever a small grid-cell is estimated to be unstable while being contextually surrounded by stable grids, the choice on which action is more appropriate to take from a risk perspective becomes unclear. Most of these issues do not affect a valid alternative represented by a Slope Unit (SU) partition. These are mapping units bounded by ridges catchment/subcatchment divides and streamlines (Carrara et al., 1991, 1995). Therefore, they are expressed at a spatial scale compatible with slope stabilization procedures. Besides, they offer a landscape subdivision which respects the morpho-dynamic behavior of a theoretical landslide initiation process. They also come with some limitations although of minor impact to the overall landslide susceptibility assessment. In fact, if for the grid-cell case assigning a predictor value for a given unit is a straightforward task because the resolution is usually identical to the DEM and other satellite-derived properties. Conversely, a SU case implies that within a single unit thousands if not millions of values are associated to terrain and thematic properties. In other words, a SU choice requires an additional step which corresponds to the aggregations or 
upscaling of properties that are represented over space with a much higher resolution. And, this aggregation step is not standardized in the literature. Oftentimes, mean and standard deviation values are extracted for numerical properties at the scale of the single SU (e.g., Guzzetti et al., 2006). But, these could also be expressed via different summary distribution metrics, e.g. such as quantiles (Amato et al., 2019). Similarly, it is not standardized the way categorical properties such as lithology or land use are aggregated at the SU scale. At times the literature reports cases where the dominant class contained in a given $\mathrm{SU}$ is used to represent the whole unit itself (e.g., Schlögel et al., 2018). However, examples can also be found where percentages of several classes' extents with respect to the given SU are used instead (e.g., Castro Camilo et al., 2017).

Nevertheless, SUs are undoubtedly a valid option for landslide susceptibility assessments, since they are able to capture the variability of the landscape associated with the failure process, by maximizing homogeneity of slope steepness and aspect within a single unit and heterogeneity of the same between adjacent SUs (Alvioli et al., 2016). In this study, we select a SU partition of the Italian territory. In addition to the above mentioned reasons, for such a large study area, choosing a small regular lattice would have inevitably produced several tens of millions of grid-cells. In turn this would have required massive computational costs. The alternative of seeking a reasonable size of the dataset would have instead produced grid-cells which would have been individually very coarse (in the order of hundreds and even up to thousands of meters). Therefore, a single grid-cells may have spanned over two or more small subcatchment ridges, neglecting any geomorphological representation of the landscape under study. The SUs we used were made available by Alvioli et al. (2016) at the following address (link here). In their work, Alvioli and co-authors computed SUs for the whole Italian territory with an exceptional level of detail. As a result, the size of most the mapping unit was confined below a single kilometer squared. This is shown in Figure 4, where we summarized the distribution of all the SUs' planimetric areas, ranging from approximately $0.1 \mathrm{~km}^{2}$ to $10 \mathrm{~km}^{2}$.

To support the analyses in this study, we assigned stable conditions' labels to SU not intersected by landslides contained in the Input dataset. On the contrary, we assigned an unstable label to all the SUs intersecting a landslide. Below we will provide a description of the predictor set we chose and we stress the reader that to aggregate each predictor at the SU scale, we used the mean and standard deviation criterion for continuous properties as well as the dominant class for categorical properties.

\subsection{Predictor variables}

To support the modeling protocol at a scale comparable to the whole Italian territory, we selected a broad set of predictors aimed at expressing properties known or assumed to influence landslide occurrences. In Tab.1, we provide a general overview of these predictors by grouping them into macro-classes, namely geological, seismic, anthropic, terrain and hydrological characteristics. And, in the following subsections, we will provide more details on 


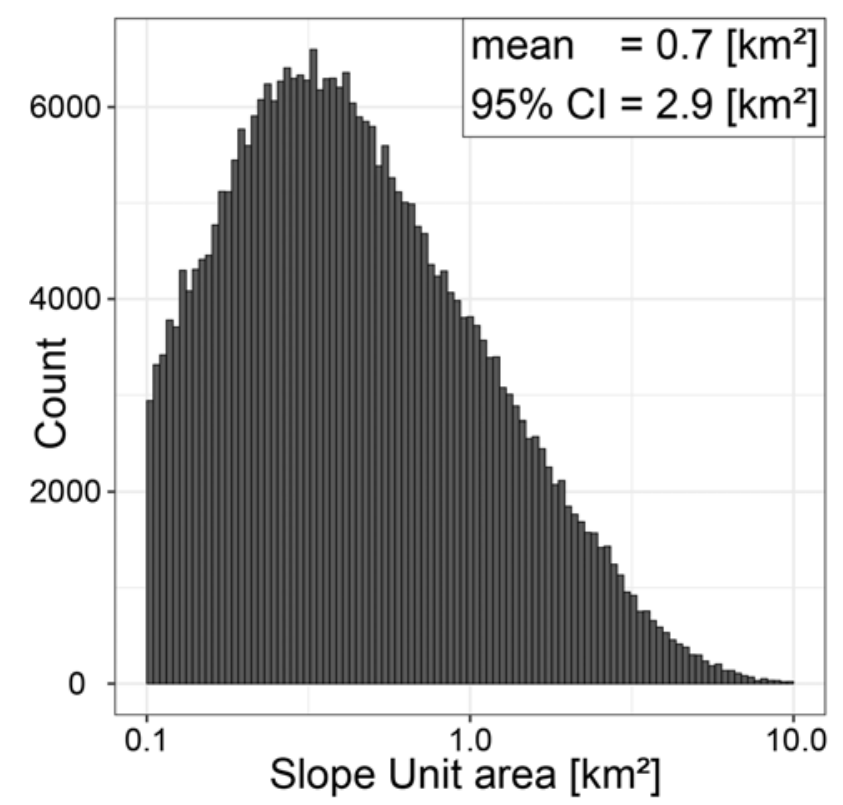

Figure 4: Distribution of SU planimetric areas. The x-axis is plotted in logarithmic scale to improve the figure readability. The $95 \%$ Confidence Interval is calculated as the difference between the 97.5 and the 2.5 percentiles of the $\mathrm{SU}$ area.

each specific characteristic. Before describing these properties, it is important to note that some of them may be related to one another. In other words, one or more predictors may explain the variability of another one, or even more than just one. More specifically, this relation may behave quite linearly which, for statistically-based models, typically hinders the algorithm convergence to the solution. This situation (commonly referred to collinearity) arises especially for linear models whenever the design matrix is not invertible (in case of strong linear dependence among predictors) or close to being non-invertible (in case of milder linear dependence among predictors). The latter will still negatively affect the model by inflating the variance estimates (McElroy and Jach, 2019). However, ANNs, thanks to their intrinsic non-linearity and overparameterization, are much less sensitive to collinearity issues. In cases where this internal dependence among predictors exists, ANNs spread the estimated weights over the collinear variables to take into account the different noise levels, taking actually advantage in terms of predictive performance. Therefore, we have chosen to keep the whole predictor set (more details will be provided in Section 4.3).

Here we conclude by noting that the selected predictors are in line with those selected by other studies in the field of EQtLs susceptibility (e.g., Shao et al., 2019) and reflect factors considered particularly favorable in inducing landslides in the Italian territory by national reports (link here). Further, as mentioned above, the possible presence of collinear predictors is handled by the neural network. And, the final number of predictors will consists of 167 layers. 
Table 1: List of the predictors assigned to each slope unit. Codes reported in "Predictors code and description" have been used to represent the results of the permutation feature importance. Predictors have been grouped as indicated in "Group" to perform the combination-groups analysis.

\begin{tabular}{|c|c|c|c|c|c|c|c|}
\hline Group & Type & & Predictors code and description & Group & Type & & Predictors code and description \\
\hline \multirow{5}{*}{ 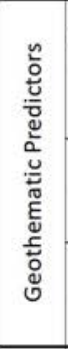 } & \multirow{2}{*}{$\begin{array}{c}\text { Geomorphon } \\
\text { (categorical - } \\
10 \text { classes) }\end{array}$} & \multirow{2}{*}{10} & \multirow{2}{*}{$\begin{array}{l}\text { Class of "geomorphon" which covers most of } \\
\text { the area of the Slope Unit (SU), calculated from } \\
\text { the Digital Elevation Model (DEM) at } 20 \mathrm{~m} \text {. }\end{array}$} & \multirow{33}{*}{ 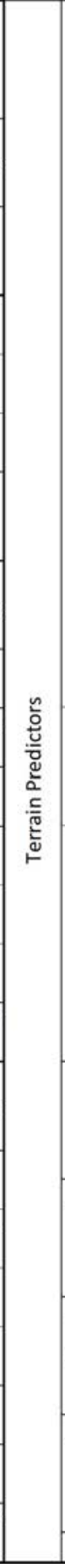 } & \multirow{12}{*}{ Curvature } & 143 & $\begin{array}{l}\text { The average Tangential Curvature of a SU, } \\
\text { calculated from the DEM at } 20 \mathrm{~m} \text {. }\end{array}$ \\
\hline & & & & & & \multirow{2}{*}{144} & \multirow{2}{*}{$\begin{array}{l}\text { The standard deviation of the Tangential } \\
\text { Curvature of a SU, calculated from the DEM at } \\
20 \mathrm{~m} \text {. }\end{array}$} \\
\hline & \multirow{2}{*}{$\begin{array}{l}\text { Lithology } \\
\text { (categorical - } \\
21 \text { classes) }\end{array}$} & \multirow[b]{2}{*}{31} & \multirow{2}{*}{$\begin{array}{l}\text { Lithology covering most of the SU area; it is } \\
\text { taken from the geological map of Italy at a scale } \\
\text { of } 1: 50.000 \text { or } 1: 100.000 \text {. }\end{array}$} & & & & \\
\hline & & & & & & 145 & $\begin{array}{l}\text { The average Profile Curvature of a SU, } \\
\text { calculated from the DEM at } 20 \mathrm{~m} \text {. }\end{array}$ \\
\hline & $\begin{array}{c}\text { Soil Type } \\
\text { (categorical - } \\
91 \text { classes) }\end{array}$ & 122 & $\begin{array}{l}\text { Type of soil that covers most of the area of the } \\
\text { SU; it is taken from the ecopedological map of } \\
\text { Italy at a scale of } 1: 250.000 \text {. }\end{array}$ & & & 146 & $\begin{array}{l}\text { The standard deviation of the Profile Curvature } \\
\text { of a SU, calculated from the DEM at } 20 \mathrm{~m} \text {. }\end{array}$ \\
\hline \multirow{4}{*}{ 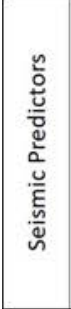 } & \multirow{4}{*}{ 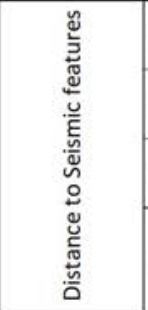 } & 123 & $\begin{array}{l}\text { The average distance of a SU from the nearest } \\
\text { seismogenic source. }\end{array}$ & & & 147 & $\begin{array}{l}\text { The average Plan Curvature of a SU, calculated } \\
\text { from the DEM at } 20 \mathrm{~m} \text {. }\end{array}$ \\
\hline & & 124 & $\begin{array}{l}\text { The standard deviation of the distance to the } \\
\text { nearest seismogenic source. }\end{array}$ & & & 148 & $\begin{array}{l}\text { The standard deviation of the Plan Curvature of } \\
\text { a SU, calculated from the DEM at } 20 \mathrm{~m} \text {. }\end{array}$ \\
\hline & & 125 & $\begin{array}{l}\text { The average distance of a SU from the nearest } \\
\text { active fault line (capable or not). }\end{array}$ & & & 149 & $\begin{array}{l}\text { The average Longitudinal Curvature of a SU, } \\
\text { calculated from the DEM at } 20 \mathrm{~m} \text {. }\end{array}$ \\
\hline & & 126 & $\begin{array}{l}\text { The standard deviation of the distance of a SU } \\
\text { from the nearest active fault line (capable or } \\
\text { not). }\end{array}$ & & & 150 & $\begin{array}{l}\text { The standard deviation of the Longitudinal } \\
\text { Curvature of a SU, calculated from the DEM at } \\
20 \mathrm{~m} \text {. }\end{array}$ \\
\hline \multirow{9}{*}{ 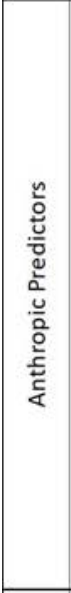 } & \multirow{9}{*}{ 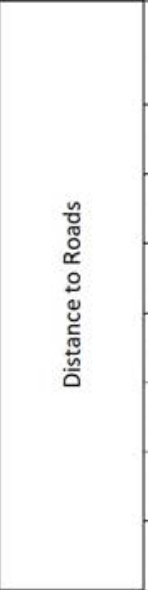 } & 127 & $\begin{array}{l}\text { Count of the pixels of a SU covered by any } \\
\text { buffer of distance from roads. The buffer ranges }\end{array}$ & & & 151 & $\begin{array}{l}\text { The average General Curvature of a SU, } \\
\text { calculated from the DEM at } 20 \mathrm{~m} \text {. }\end{array}$ \\
\hline & & & are 10,50 and $100 \mathrm{~m}$ & & & & The standard deviation of the General \\
\hline & & 128 & $\begin{array}{l}\text { Sum of the buffer values of the pixels of a SU } \\
\text { covered by any buffer of distance from roads. }\end{array}$ & & & 152 & $\begin{array}{l}\text { Curvature of a SU, calculated from the DEM at } \\
20 \mathrm{~m} \text {. }\end{array}$ \\
\hline & & 129 & $\begin{array}{l}\text { The buffer of distance from a road that takes up } \\
\text { most of the area of the SU. }\end{array}$ & & Elevation & 153 & $\begin{array}{l}\text { The average Elevation of a SU, calculated from } \\
\text { the DEM at } 20 \mathrm{~m} \text {. }\end{array}$ \\
\hline & & 130 & $\begin{array}{l}\text { The maximum value of the buffer of distance } \\
\text { from a road within a SU. }\end{array}$ & & Lievation & 154 & $\begin{array}{l}\text { The standard deviation of the Elevation of a SU, } \\
\text { calculated from the DEM at } 20 \mathrm{~m} \text {. }\end{array}$ \\
\hline & & 131 & $\begin{array}{l}\text { The average value of the buffer of distance } \\
\text { from a road within a SU. }\end{array}$ & & & 155 & $\begin{array}{l}\text { The average Exposure of a SU from north to } \\
\text { south. }\end{array}$ \\
\hline & & 132 & $\begin{array}{l}\text { The minimum value of the buffer of distance } \\
\text { from a road within a SU. }\end{array}$ & & & 156 & $\begin{array}{l}\text { The standard deviation of the Exposure of a SU, } \\
\text { from north to south. }\end{array}$ \\
\hline & & 133 & $\begin{array}{l}\text { Range (max-min) of distance values from roads } \\
\text { included in a SU. }\end{array}$ & & & 157 & The average Exposure of a SU from east to west. \\
\hline & & 134 & $\begin{array}{l}\text { Count of the pixels of a SU that fall within } 5 \mathrm{~m} \text { of } \\
\text { distance from roads. }\end{array}$ & & & 158 & $\begin{array}{l}\text { The standard deviation of the Exposure of a SU, } \\
\text { from east to west. }\end{array}$ \\
\hline & & 135 & $\begin{array}{l}\text { Count of the pixels of a SU covered by any } \\
\text { buffer of distance from rivers. The buffer ranges }\end{array}$ & & Slop & 159 & $\begin{array}{l}\text { The average Slope of a SU, calculated from the } \\
\text { DEM at } 20 \mathrm{~m} \text {. }\end{array}$ \\
\hline & & & are 10,50 and $100 \mathrm{~m}$ & & & 160 & The standard deviation of the Slope of a SU, \\
\hline & & 136 & Sum of the buffer values of the pixels of a SU & & & & calculated from the DEM at $20 \mathrm{~m}$. \\
\hline & & & covered by any buffer of distance from rivers. & & & 161 & The average TWI of a SU, calculated from the \\
\hline 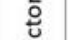 & 尝 & 137 & The buffer of distance from a river that takes up & & Wetness & & DEM at $20 \mathrm{~m}$. \\
\hline 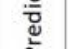 & 这 & & most of the area of the SU. & & Index (TWI) & 162 & The standard deviation of the TWI of a SU, \\
\hline$\frac{\pi}{8}$ & $3^{\pi}$ & 138 & from a river within a SU. & & & 163 & The average TPI of a SU, calculated from the \\
\hline 응 & $\stackrel{8}{2}$ & 139 & The average value of the buffer of distance & & & 100 & DEM at $20 \mathrm{~m}$ \\
\hline 음 & $\underset{\mathrm{C}}{\mathrm{C}}$ & 130 & from a river within a SU. & & (TPI) & 164 & The standard deviation of the TPI of a SU, \\
\hline ج্̀ & $\stackrel{\check{n}}{0}$ & 140 & The minimum value of the buffer of distance & & & & calculated from the DEM at $20 \mathrm{~m}$. \\
\hline & & & from a river within a SU. & & & 165 & The average TRI of a SU, calculated from the \\
\hline & & 141 & Range (max-min) of distance values from rivers & & Ruggedness & & DEM at $20 \mathrm{~m}$. \\
\hline & & & included in a SU. & & Index (TRI) & 166 & The standard deviation of the TRI of a SU, \\
\hline & & 142 & Count of the pixels of a SU that fall within $5 \mathrm{~m}$ of & & & & calculated from the DEM at $20 \mathrm{~m}$. \\
\hline & & & distance from rivers. & & Area & 167 & SU area. \\
\hline
\end{tabular}




\subsubsection{Geothematic predictors}

We considered three geo-thematic properties, detailed below:

1. Landforms are specific geomorphic features on the earth's surface which encompass both large-scale terrains such as plains or mountain ranges and small-scale characteristics such as single hills or valleys (Jacek, 1997). The work of Guisan et al. (1999) first and Jenness (2006) later has pioneered the automatic extraction of such features from DEMs. More recently, Jasiewicz and Stepinski (2013) have implemented an efficient automatic classification tool for landforms named geomorphon (link here), which returns 10 terrain morphologies in 10 classes: 1) flat, 2) summit, 3) ridge, 4) shoulder, 5) spur, 6) slope, 7) hollow, 8) footslope, 9) valley, 10) depression. In this study, we used geormophon to initially calculate the ten landforms and in a subsequent step, we have aggregated this information at the SU scale by assigning to a given mapping unit the most representative class (or the class with the largest planimetric extent).

2. Similarly, we have assigned to each SU the predominant lithological type. This geological information was retrieved from the Geological Map of Italy at 1:500,000 scale. This map was based on 1:100,000 and 1:50,000 national geological cartography or geological maps (Tacchia et al., 2005). Overall, after the aggregation step, 21 lithology classes have been assigned to SUs across the whole Italian territory. Tab.2 offers a description of each class.

3. The predominant soil type was assigned to each $\mathrm{SU}$ on the basis of the european soil map compiled by the European Commission - Joint Research Centre (Finke and Montanarella, 2001). In this map, soils type classes are classified according to the World Reference Base (WRB) system, which consists of a two-levels terminology. The first level defines the Reference Soil Groups whereas the second level is nested within the first and consists of a set of principal and supplementary qualifiers (for more details, see link here. In this study, SUs have been classified on the basis of 91 soil types classes, which have been used for modeling purposes and mainly belong to the Reference Soil Groups reported in Tab.3.

Concerning the categorical predictors, slope units have been labelled with "1" in correspondence of the predominant classes of geomorphon, soil type and lithology, and " 0 " for all the other classes.

\subsubsection{Seismic predictors: distance to seismogenic features}

Seismic information has been considered in the form of Euclidean distance to the nearest active fault and the Euclidean distance to the nearest seismogenic source. Specifically, for each $\mathrm{SU}$, the mean distance value and its standard deviation have been computed. Data required to produce these predictors have been accessed from the Database of Individual Seismogenic 
Table 2: Description of the classes of the categorical predictor "Lithology".

\begin{tabular}{|c|c|}
\hline Lithology & Description \\
\hline Volcanic rocks & Lavas, pyroclastic rocks and ignimbrites. \\
\hline Ophilytes & $\begin{array}{l}\text { Gabbri and anorthosites; Basalts, spilites, hyaloclastites; Serpentines, } \\
\text { serpentine schists and chloritoscists; Metabasites, eclogites, } \\
\text { amphibolites, green stones s.l. }\end{array}$ \\
\hline Metamorphic rock & Granitoid gneiss. \\
\hline High-grade Metamorphic & $\begin{array}{l}\text { Acid granulites and biotitic-sillimanitic granatiferous gneisses } \\
\text { (sometimes with cordierite), with marbles, amphibolites. }\end{array}$ \\
\hline Mid-grade Metamorphic & $\begin{array}{l}\text { Mica schists and paragneisses with amphibolites, phyllites, quartzites } \\
\text { and marbles. }\end{array}$ \\
\hline Low-grade Metamorphic & $\begin{array}{l}\text { Fylladi with albitic paragneisses, porphyroids, marbles and green } \\
\text { schists. }\end{array}$ \\
\hline Intrusive rocks & Granites, granodiorites, tonalites and rare diorites. \\
\hline $\begin{array}{l}\text { Chaotic sedimentary } \\
\text { complexes }\end{array}$ & $\begin{array}{l}\text { Sandstones (including turbidite) and clays, in places with evaporites } \\
\text { and subordinately limestone. }\end{array}$ \\
\hline Arenaceous formations & Sandstones and conglomerates, sometimes turbidites. \\
\hline Limestones & $\begin{array}{l}\text { Limestones, sometimes arenaceous, and marl metamorphosed into } \\
\text { carbonate schists (marbles, phyllites, etc.). }\end{array}$ \\
\hline Clayey Schist & Clayey Schist, sometimes carbonaceous. \\
\hline Flysch & $\begin{array}{l}\text { Clayey and clayey-calcareous units often with turbidite character, } \\
\text { sometimes including the lower Miocene. }\end{array}$ \\
\hline Conglomerates & $\begin{array}{l}\text { Clastic deposits locally with marl including, at times, the } \\
\text { Carboniferous. }\end{array}$ \\
\hline Marls & Pelagic facies marls, sometimes with flint. \\
\hline Evaporites & Chalky-sulphurous formation. \\
\hline Organogenic limestone & Debris and organogenic limestones, "bench" type. \\
\hline Clays & Clays and marls, locally with holistostromes. \\
\hline Sands & $\begin{array}{l}\text { Conglomerates and sandstones, sometimes including the Upper } \\
\text { Permian. }\end{array}$ \\
\hline Fluvial deposits & $\begin{array}{l}\text { Debris accumulations, alluvial and fluviolacustri deposits, current } \\
\text { beaches }\end{array}$ \\
\hline Glacial deposits & Glacial deposits. \\
\hline Travertine & Travertines (sometimes Holocene). \\
\hline
\end{tabular}


Table 3: Description of the reference soil groups compared in the classes of the categorical predictor "Soil type".

\begin{tabular}{|c|c|c|}
\hline Soil Type & WRB Code & \begin{tabular}{|c|} 
Description \\
\end{tabular} \\
\hline Andosols & AN & $\begin{array}{l}\text { Soils distinguished by Fe/Al chemistry - Allophanes or Al-humus } \\
\text { complexes. Andosols are generally quite young soils found in } \\
\text { volcanic areas formed in volcanic tephra. Andosols are usually } \\
\text { defined as soils containing high proportions of glass and } \\
\text { amorphous colloidal materials, including allophane, imogolite and } \\
\text { ferrihydrite. }\end{array}$ \\
\hline Calcisols & $\mathrm{CL}$ & $\begin{array}{l}\text { Accumulation of moderately soluble salts or non-saline } \\
\text { substances - Accumulation of secondary carbonates. Calcisols } \\
\text { are developed in mostly alluvial, colluvial and aeolian deposits of } \\
\text { base-rich weathering material. They are found on level to hilly } \\
\text { land in arid and semi-arid regions. The natural vegetation is } \\
\text { sparse and dominated by xerophytic shrubs and trees and/or } \\
\text { ephemeral grasses. }\end{array}$ \\
\hline Cambisols & $\mathrm{CM}$ & $\begin{array}{l}\text { Soils with little or no profile differentiation - Moderately developed. } \\
\text { Cambisols are developed in medium and fine-textured materials } \\
\text { derived from a wide range of rocks, mostly in alluvial, colluvial and } \\
\text { aeolian deposits. }\end{array}$ \\
\hline Fluvisols & FL & $\begin{array}{l}\text { Soils with little or no profile differentiation - Stratified fluviatile, } \\
\text { marine and lacustrine sediments. Fluvisols are found on alluvial } \\
\text { plains, river fans, valleys and tidal marshes on all continents and } \\
\text { in all climate zones. Under natural conditions periodical flooding is } \\
\text { fairly common. The soils have a clear evidence of stratification. } \\
\text { Soil horizons are weakly developed, but a distinct topsoil horizon } \\
\text { may be present. }\end{array}$ \\
\hline Leptosols & LP & $\begin{array}{l}\text { Soils with limitations to root growth - Thin or with many coarse } \\
\text { fragments. Leptosols are very shallow soils over hard rock or a } \\
\text { deeper soil that is extremely gravelly and/or stony. Leptosols can } \\
\text { be found on hard rocks or where erosion has kept pace with soil } \\
\text { formation or removed the top of the soil. The very shallow, less } \\
\text { than } 10 \mathrm{~cm} \text { deep, Lithic Leptosols in mountain regions are the } \\
\text { most extensive Leptosols on Earth. }\end{array}$ \\
\hline Luvisols & LV & $\begin{array}{l}\text { Soils with clay-enriched subsoil - High-activity clays, high base } \\
\text { status. The main characteristic is an argic horizon, a subsurface } \\
\text { zone with higher clay content than the material above it. This } \\
\text { typically arises as clay is washed downward by water and } \\
\text { accumulates at greater depth. }\end{array}$ \\
\hline Regosols & RG & $\begin{array}{l}\text { Soils with little or no profile differentiation - No significant profile } \\
\text { development. Regosols are developed in unconsolidated } \\
\text { materials. Regosols are extensive in eroding lands, in particular in } \\
\text { arid and semi-arid areas and in mountain regions. }\end{array}$ \\
\hline
\end{tabular}


Sources of Italy. An Individual Seismogenic Source is obtained by parameterizing the geometry and kinematics of large active faults considered capable of generating earthquakes with a magnitude $\left(\mathrm{M}_{w}\right)$ greater than 5.5 (Basili et al., 2008; DISS-Working-Group, 2018). This corresponds to an active fault that has accumulated some displacement in the recent past and can be considered very likely to produce a new offset in the near future (link here). The use of PGA as a predictor of landslide triggering was avoided since it could be problematic and affected by conceptual mistakes. More in particular, the PGA derived from official hazard maps (link here) does not represent the distribution of shaking effects during an earthquake, i.e. are not representative for a earthquake-induced landslide scenario, and as a consequence it cannot be linked to the effects inventoried in the CEDIT catalogue. As a conceptual example, for the slope units including inventoried landslides, the triggering PGA values (i.e. related to the shake map of the occurred earthquake) could be significantly lower than the PGA values expected on the basis of the National seismic hazard map. On the other hand, the use of PGA derived from shaking maps at the location of each inventoried landslide in the CEDIT catalogue is not available for the whole dataset, especially in case of not recent earthquakes. Moreover, it is worth noting that in case of a prediction scenario the distribution of PGA values is not directly linked to the seismogenic fault distance, as local amplification effects can occur and modify the expected ground motion respect to what provided based on the National attenuation law (Sabetta and Pugliese, 1987). In light of this, we preferred the distances from active faults and seismogenic sources to the more common PGA. In fact, on the one hand, the Distance from DISS seismogenic sources can be directly measured and can account for the local variability of ground acceleration that takes place during an earthquake. On the other hand, by also considering the distance from active fault segments we contextually provided a more capillary distribution of the possible seismogenic sources.

\subsubsection{Terrain predictors}

Concerning Terrain predictors, we used the 20m DEM released by the Italian Institute for Environmental Research in 2013 (link here). And, for each slope unit, we calculated the mean value and the standard deviation of the following derivatives:

- Elevation (e.g., Ayalew and Yamagishi, 2005) can be considered as a proxy for climaterelated characteristics (e.g., ground temperature or even the precipitation itself when high ridges play the role of meteorological barriers). And, its standard deviation per slope unit mimics the signal of surface roughness.

- Eastness and Northness, these are computed as the sine and cosine of the Aspect expressed in radians, respectively (Lombardo et al., 2018). These are two linear components of the nonlinear slope exposition signal, a common proxy for strata attitude and localized dry/wet soil conditions. 
- Slope gradient (Zevenbergen and Thorne, 1987) expresses the potential gravitational forces acting over a given slope.

- General, Longitudinal and Tangential Curvatures (Evans, 1980; Wood, 1996), Planar and Profile Curvatures (Heerdegen and Beran, 1982). Plan and profile curvatures carry the signal of the potential soil availability, and potential small scale hydraulic and gravitational forces (Ohlmacher, 2007). Conversely, cross-sectional curvature measures the curvature perpendicular to the down slope direction. As a result, it detects small scale features such as channels. Longitudinal curvature plays a similar role but parallel to the down slope direction (Patel and Sotiropoulos, 1997).

- Topographic Positioning Index (TPI, De Reu et al., 2013) measures the difference between elevation of a focal cell and the average elevation within a predetermined radius.

- Topographic Roughness Index (TRI, Riley et al., 1999) expresses rough terrains conditions.

- Topographic Wetness Index (TWI, Beven and Kirkby, 1979) expresses the terrain tendency to retain water at a given location, as a function of local slope steepness and upslope contributing areas. Therefore, it conveys the information related to potential high pore pressure conditions distributed over the landscape or the presence of open floodplains.

- The area of each slope unit $\left(\mathrm{A}_{S U}\right)$ controls the availability of potential material to fail.

\subsubsection{Anthropic predictors: distance to roads}

An ideal situation to inform any predictive model of the potential destabilizing effect of road cuts would be to collect the exact location and height of the cut. However, such information is available only for the location component and no height characteristics can be accessed for the whole Italian road network. For this reason, we opt to compute the Euclidean distance from roads at buffers equal to 5, 10, 50 and 100 meters. Subsequently, a series of statistical metrics of the distances to roads have been calculated for each SU, namely mean, maximum and minimum distance of the unit from the closest road and the portion of the territory extending within certain distance ranges. Therefore, the following statistics have been calculated for every slope unit using the Zonal Statistics Plugin, in QGis 3.10.4 (Graser, 2016).

- Count: the count of the number of pixels at a $<100 \mathrm{~m}$ distance;

- Sum: the sum of the pixel distance values;

- Mean: the mean distance; 
- Min: the minimum distance;

- Max: the maximum distance;

- Range: the range (max - min) of distance;

- Majority: the most represented distance within a slope unit;

- Count $<5$ : the count of the number of pixels at a $<5 \mathrm{~m}$ distance.

\subsubsection{Hydrological predictors: distance to watercourses}

The Euclidean distance from watercourses has been computed similarly to the road network case. This time though, we extracted ten equally spaced (100 m wide) buffer zones from 0 up to $1000 \mathrm{~m}$ from each streamline. The same summary statistics calculated for the distance from the road network have been computed also for the hydrological network with respect to each slope unit.

\subsection{Artificial Neural Network}

The used ANN architecture has been optimized to perform a binary classification between stable and unstable slope units. Stable slope units are those SUs with no EQtLs while unstable SUs contain at least one landslide of the Input dataset. The ANN training is performed on balanced classes datasets. The used network is a "shallow" ANN whose architecture is a two-layers fully connected feed-forward network. For the hidden layer, a sigmoid activation function has been considered. The output layer is a "softmax layer", in which the outputs are normalized into probabilities proportional to the exponentials of the input values. The network is trained by scaled conjugate gradient backpropagation. To limit any overfitting effect an "early stopping by validation" training criterion has been adopted. The classification process associates a probability value, from 0 to 1 , to each slope unit to be susceptible to EQtLs. Finally, an a-posteriori threshold of 0.5 has been selected to discriminate between stable and unstable classes. In order to be correctly trained to distinguish between stable and unstable slope units, the ANN needed to learn from samples of both classes. We set a fixed number of samples per class (equal to the number of all the slope units with landslides). Therefore, the Input dataset counted for 523 positives (i.e. slope units with landslides) and an equal number of negatives (i.e. slope units without landslides), these latter chosen randomly from the larger number available. The Input dataset was then split as follows: $70 \%$ of samples was used to train the network, $15 \%$ was used for validation and $15 \%$ as test dataset. The training dataset is used to optimise the weights and the bias assigned to each node of the ANN. After each step of the iterative training, the ANN classification is applied also on the validation dataset and the classification performances on the two datasets are monitored. As the classification performance continues to improve on the training dataset but worsens on the validation dataset, the training process is early stopped and overfitting of the model 
is avoided. Finally, the test dataset is a completely independent dataset used to test the reproducibility of performances obtained on the first two sets. In order to build a statistically significant distribution of the classification results and performance metrics, we replicated the training procedure 100 times. To ensure the maximum statistical independence, for each of the 100 replicates, the training, validation and test datasets are recreated from scratch as described before. Furthermore, the initial values of ANN weights and biases are randomly changed. Fixed the ANN architecture, some of the operating network hyperparameters, and in particular the number of nodes in the hidden layer, have been tuned to achieve the best and more reliable performances. In the "tuning" tests, the ANN performance was calculated as True Positive Rate (TPR, or Recall). TPR is the ratio between the number of true positives (i.e. those samples correctly predicted by the model as belonging to the given class) and the sum of true positives and false negatives (i.e. those samples the model predicted as belonging to a given class while they were not). A number varying from 1 to 6 nodes in the hidden layer has been tested. It resulted in a TPR increase as the number of nodes increased. The number of nodes was finally set to 4 as being the smallest number of nodes, which still produced a significant increase in performances. At the end of each of the 100 training replicates, the ANN was run on all the SUs, covering the whole national territory. The mean of the probability values output from the 100 classification replicates, as well as their standard deviation, was calculated and was used to plot the Earthquake-induced Landslide Susceptibility Map of Italy.

\subsection{Performance assessment: validation routines}

Typically, classification algorithms do not directly provide the membership of a given sample to one of the possible classes. Rather, they provide a probability value that the given sample belongs to one of the possible classes. In the case of binary classification, this type of information makes it possible to establish a certain threshold value to associate a particular sample to one of the two possible classes: positive and negative (or presence and absence). Only those samples for which the classification algorithm determines probability values of belonging to the positive class greater than the threshold value will be classified as such. The most appropriate way to investigate the discriminatory capabilities of a binary classifier for each possible value of the discrimination threshold between 0 and 1 is commonly the Receiver Operating Characteristic (ROC; Rahmati et al., 2019) plot. ROC plots, for any threshold value between 0 and 1 , report the TPR on the $y$-axis and the False Positive Rate (FPR or fall-out) on the $\mathrm{x}$-axis. FPR is defined as the ratio between false positives and all the negatives, namely false positives + true negatives. False positives are samples classified as belonging to the class of interest while they were actually not, whereas true negatives are those samples correctly predicted by the model as not belonging to the class of interest. The Area Under the Curve (AUC) is strictly linked to the shape of the ROC curve and it is a good proxy of the overall capability of a model to distinguish between two classes, regardless of what classification threshold is chosen. AUC assumes values between 0 and 1 gradually 
increasing with the classification capabilities of the model. For example, an AUC value of 0.5 corresponds to a random sample classification. If AUC is 1 the model is perfectly able to distinguish between positive class and negative class (Hosmer and Lemeshow, 2000). As said, a probability threshold of 0.5 has been chosen to classify each slope unit as stable or unstable. The choice of this threshold value is the natural choice when training binary classifiers on balanced datasets (see, Frattini et al., 2010). This choice is also confirmed by examining the point of the average ROC corresponding to a threshold value of 0.5 (as also reported in Fig.5a). This point is in fact the closest one to a TPR equal to 1 and an FPR equal to zero. A threshold value of 0.5 is therefore the best compromise to obtain both high TPR and low FPR values. Once the threshold value has been chosen, it is possible to further investigate the obtained discrimination capabilities by the means, for instance, of a Confusion Plot (Rossi and Reichenbach, 2016; Lombardo et al., 2020b). Conversely to ROC (and AUC), Confusion Plot is a threshold-dependent method to evaluate the classification performance. It has TPR on the $\mathrm{y}$-axis and TNR on the $\mathrm{x}$ one. In model performance evaluation, TNR stands for True Negative Rate and is the ratio between the number of true negatives and the sum of true negatives and false positives. In this study, TNR refers to the success rate in classifying slope units as belonging to the "stable" class and TPR refers to the "unstable" one. Against this background, the performance obtained by the network in this study has been represented by means of both Confusion Plot and ROC (plus AUC), which are considered good indicators of the general performance of a model and commonly adopted in the scientific literature (Lombardo and Mai, 2018). Furthermore, we represented the importance assumed by each predictor during the classification by performing a Feature Importance analysis. This procedure highlights those predictors that gave a major contribution for the success of the susceptibility analysis. To make this, the Permutation Feature Importance (PFI) was adopted. The method is based on the assumption that a random variation of the value of an important predictor has a negative impact on the performance of the model greater than that of the random variation of a less important predictor (Putin et al., 2016). Specifically, to evaluate the importance of a given predictor for a given model, the PFI method is based on the comparison between the performances obtained with the original dataset and those obtained with a dataset in which the values of the predictor of interest are randomly permuted. The permutation allows the random variation of the predictor while preserving the natural distribution of the values of the predictor itself (Gao et al., 2020). By measuring the reduction of the model performance, the relative importance of the predictor can be evaluated (Putin et al., 2016). In the current study, the PFI was applied to each of the predictors. The model reduction, i.e. the PFI score of a predictor, was calculated as the ratio between the TPR of the non-permuted model and the TPR of the permuted model. FPI scores were evaluated for each of the $100 \mathrm{ANN}$ replicates thus allowing the evaluation of a statistical distribution of the predictors importances. Also, we grouped the 167 predictors into 5 groups (Road, Hydro, Geo, Terrain, Seismic; see Tab.1 for more details) and we investigated how the network performance varies by running the classification 20 times with 
each of all the possible different combinations of the five groups. Finally, the susceptibility map was verified by means of a comparison with the Check dataset and, for each Italian administrative region, an additional check TPR was calculated, as well as the percent of territory classified as unstable.

\section{$5 \quad$ Results}

Tab.4 shows the average values and standard deviation of the TPR, TNR and AUC general performance indicators obtained through the 100 ANN replicates. The results are reported for the three types of dataset we considered, namely training, validation and test. Furthermore, we also report the values obtained for the dataset composed of the sum of the three subsets (All). The results in the table show high performances for the three indicators considered. The average values for the three datasets are also comparable, demonstrating that the approach followed is able to limit any evident overfitting effect and the consequent loss of generality in the slope unit classification phase. Very limited values of the standard deviations also demonstrate the robustness of the method, which is able to obtain comparable performances regardless of the specific datasets used in each of the 100 replicates.

Table 4: Performance of the ANN after 100 replicates. For each indicator, mean and standard deviation are provided.

\begin{tabular}{|c|c|c|c|c|c|c|}
\hline & Mean TPR & SD TPR & Mean TNR & SD TNR & Mean AUC & SD AUC \\
\hline Train & 0.86 & 0.02 & 0.85 & 0.02 & 0.92 & 0.01 \\
\hline Val & 0.83 & 0.03 & 0.84 & 0.03 & 0.91 & 0.02 \\
\hline Test & 0.81 & 0.04 & 0.79 & 0.03 & 0.89 & 0.02 \\
\hline All & $\mathbf{0 . 8 5}$ & $\mathbf{0 . 0 2}$ & $\mathbf{0 . 8 4}$ & $\mathbf{0 . 0 2}$ & $\mathbf{0 . 9 1}$ & $\mathbf{0 . 0 1}$ \\
\hline
\end{tabular}

Considering the comparability of the performances obtained on the three training, validation and test datasets, for the following results it was considered appropriate to report those obtained on the overall dataset composed by the three.

Figure 5a shows (in grey) the ROC obtained for each of the 100 replicates of the ANN trainings. The average ROC is shown in red. In this study $\mathrm{AUC}=0.91$ has been reached on average, with a standard deviation smaller than 0.02 (see Fig.5a and Tab.4). Beside the best classification threshold that resulted in being about 0.5, in Fig.5a, the TP and FP rates related to other eight different thresholds (from 0.1 to 0.9 ) are indicated by the means of black circles. The TPR and FPR values associated to different threshold values allow a deeper interpretation of the results in case of a direct analysis of the EQtLs susceptibility probability value that the model associates to each SU. As an example, by choosing a threshold value of 0.8 a very low FPR (about 0.06 ) is obtained. This means that only a very limited fraction of the stable SU would be wrongly classified as unstable. As a result, those SUs that have been classified with a probability higher than 0.8 to be susceptible to EQtLs, are statistically 

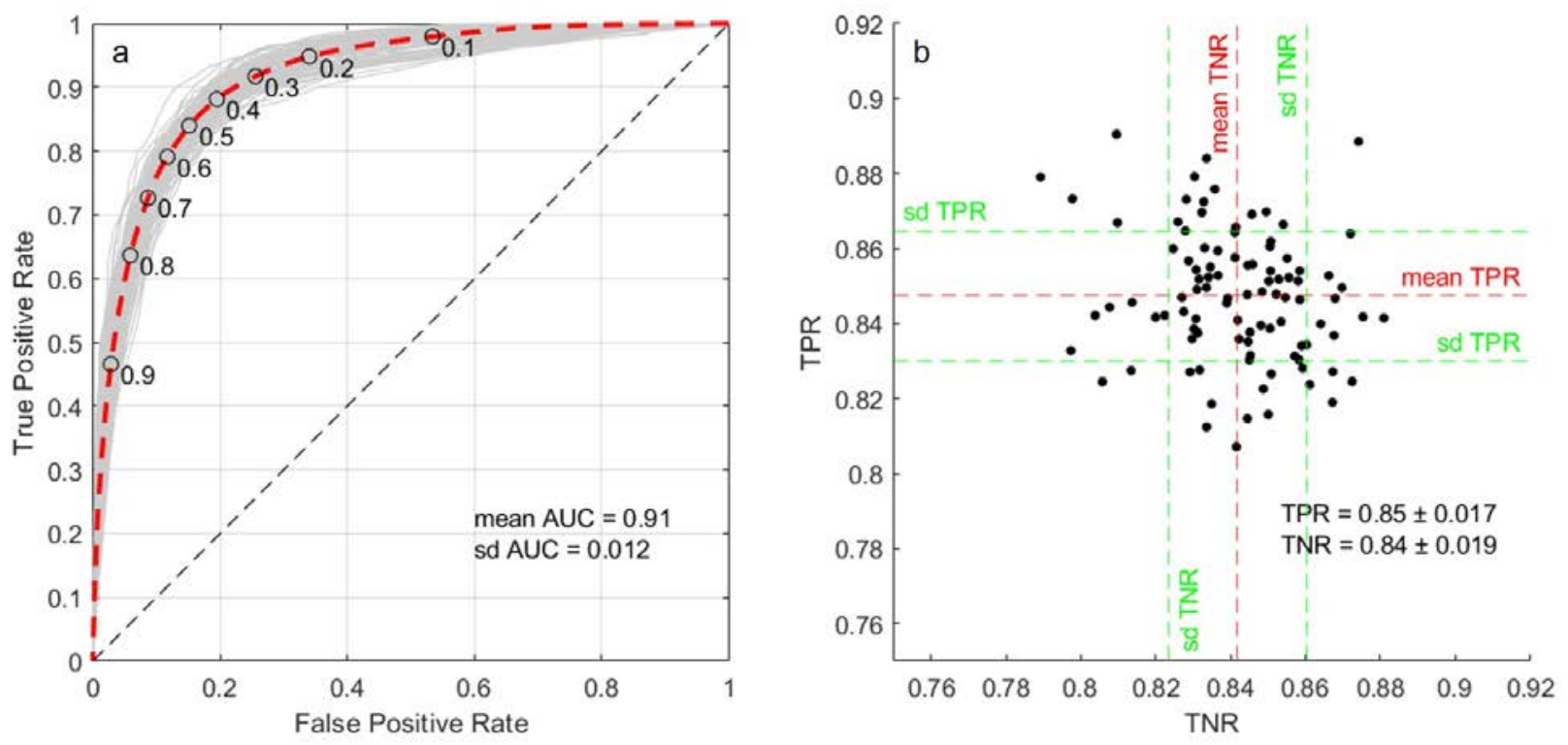

Figure 5: a) ROC of each of the 100 ANN replicates with, in red, the resulting average. Circles represent different classification thresholds. Also AUC mean and standard deviation values are reported. b) Confusion plot after 100 ANN replicates. Mean and standard deviation of TPR and TNR are reported.

very significantly likely to have actually experienced landslides/be true positives. Figure 5b) shows, for the 100 ANN replicates, the values of the TPR parameter according to the TNR parameter. Mean and standard deviation ranges are also reported for both TPR and TNR. On average the classification has a very similar success rate for both classes (about 0.84) with a small standard deviation (0.02). Very similar values of TPR and TNR allow to assert that the classification is carried out with the same accuracy for both classes. The low value of the standard deviation and the absence of correlation between the values of TPR and TNR also make it possible to assert that the results obtained are robust with regard to the statistical representativeness of the samples considered and the absence of bias introduced.

\section{$5.1 \quad$ Susceptibility mapping}

After every training replicate, the ANN was applied to all the slope units of Italy and 100 susceptibility values for each SU have been generated. The mean susceptibility of each SU, and its standard deviation, after 100 replicates has been considered to produce the EQtLs susceptibility map of Italy (Figure 6a).

In the EQtLs susceptibility map of Italy, flat lowland areas have been taken out from the classification and resulted grey-coloured. Orange to red areas represent moderately to highly susceptible slope units (probability $>0.5$ ), while green to blue areas have been classified as stable. Susceptible areas are frequent in the north-eastern part of Italy and along a NW-SE oriented longitudinal belt that corresponds to the Apennine mountain chain. In 


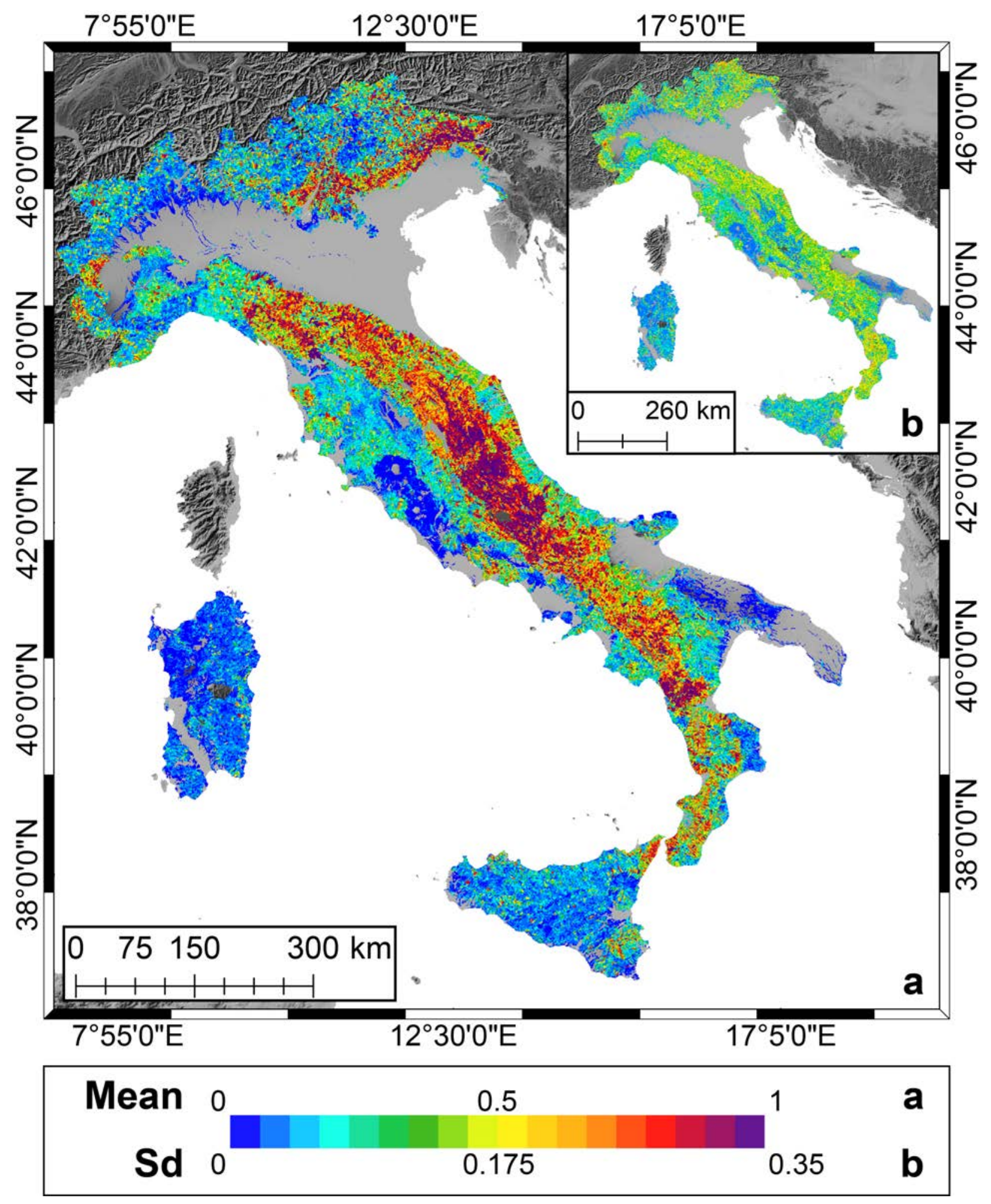

Figure 6: EQtLs susceptibility map of Italy shown as a) the mean estimated probability per SU, through the 100 ANN replicates. And, b) as the standard deviation per SU associated to the mean shown in the larger panel to the left. 
particular, red areas are located in correspondence of the epicentral area of historical strong earthquakes and a moderate density of unstable slope units is present in Calabria region, the most southern region of the Italian peninsula. Conversely, most of the western side of the peninsula and of the alpine region, in the north, are low susceptible to be affected by EQtLs. Also the south-east and the two main Italian islands, Sicily and Sardinia, are widely blue coloured. The standard deviation of the resulting classification (Figure 6b), associated to the mean susceptibility of every SU, is very low $(<0.1)$ in correspondence of the high susceptibility SUs in central Italy and in the north-east, as well as for most of the highly stable areas. In general the standard deviation of the susceptibility is low $(0.1-0.18)$ for the overall Italian territory. Higher values are present in limited spotted locations and more concentrated in Calabria region.

Figure 7 shows the error plot (Rossi et al., 2010; Lombardo et al., 2014) contextually reporting the mean susceptibility against its standard deviation, as evaluated by the 100 training replicates.

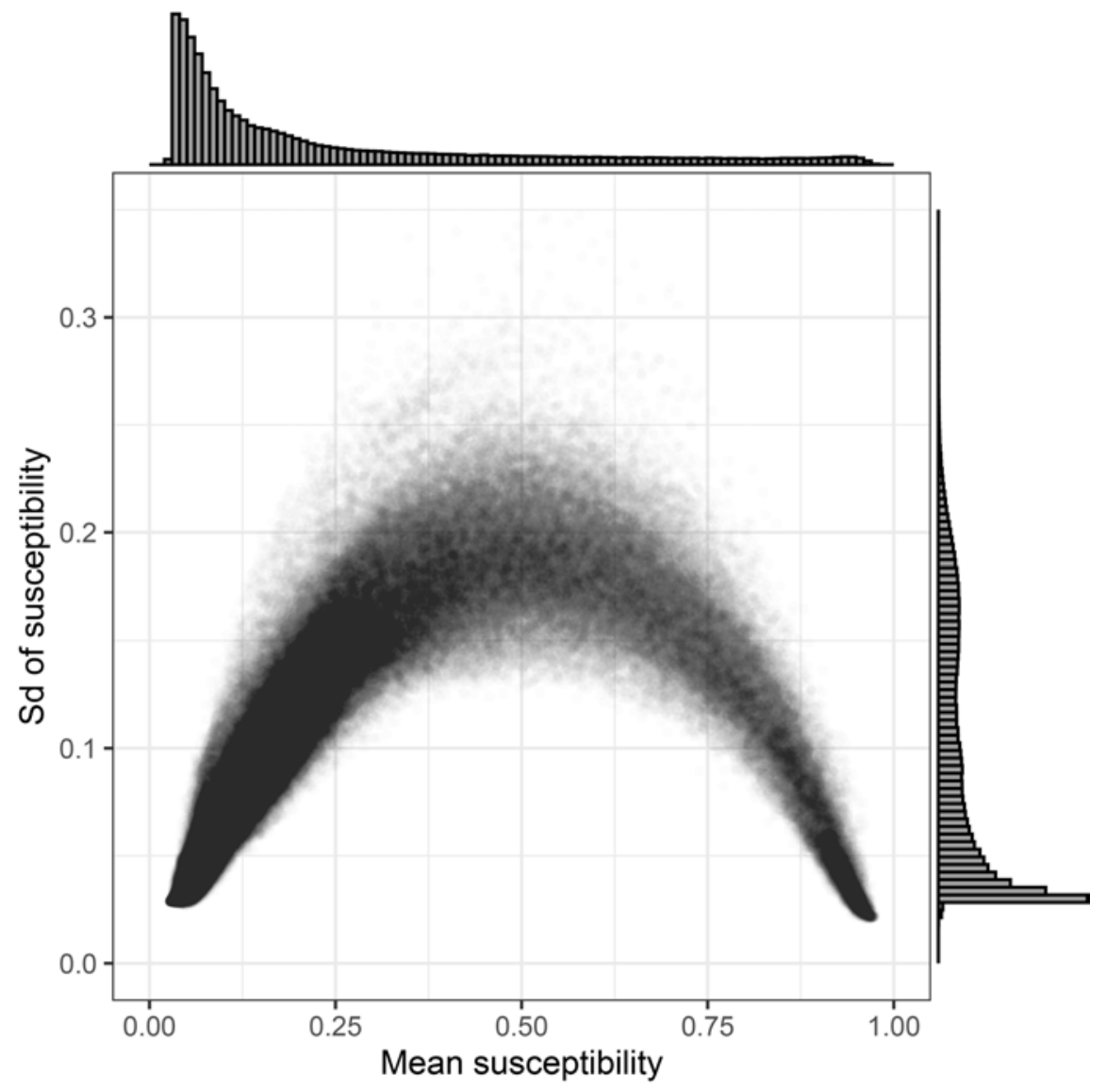

Figure 7: Error plot constructed as a scatter plot (together with marginal histograms) of the mean estimated susceptibility and associated standard deviation obtained from 100 ANN replicates. Each point in the figure corresponds to a specific SU.

This type of plot allows to evaluate the robustness of the obtained model and allows the 
decision makers to evaluate the uncertainty on how that model reliably estimates a given slope unit to be either stable or unstable. In other words, if a model assigns a high probability value to a given slope unit, but the uncertainty around that mean is large, this implies that some replicates may have classified the same slope unit to be stable. Therefore, one would ideally want to assign resources to stabilize a slope or decide whether land development investments can be made there, only if the mean prediction does not significantly change from one replicate to another. In other words, for a model to provide meaningful information, the relation between mean susceptibility and its uncertainty should produce a graphical bell shape where slope units estimated to be stable (probability close to 0) and slope units estimated to be unstable (probability close to 1) are associated with small uncertainties. And, the portion of the plot where the uncertainty is reasonable to be high corresponds to the central one. Figure 7 confirms this trend for our final susceptibility model.

A point of novelty of this study is represented by the comparison of the landslide Susceptibility map of Italy with an EQtLs dataset that was not used to train the network.
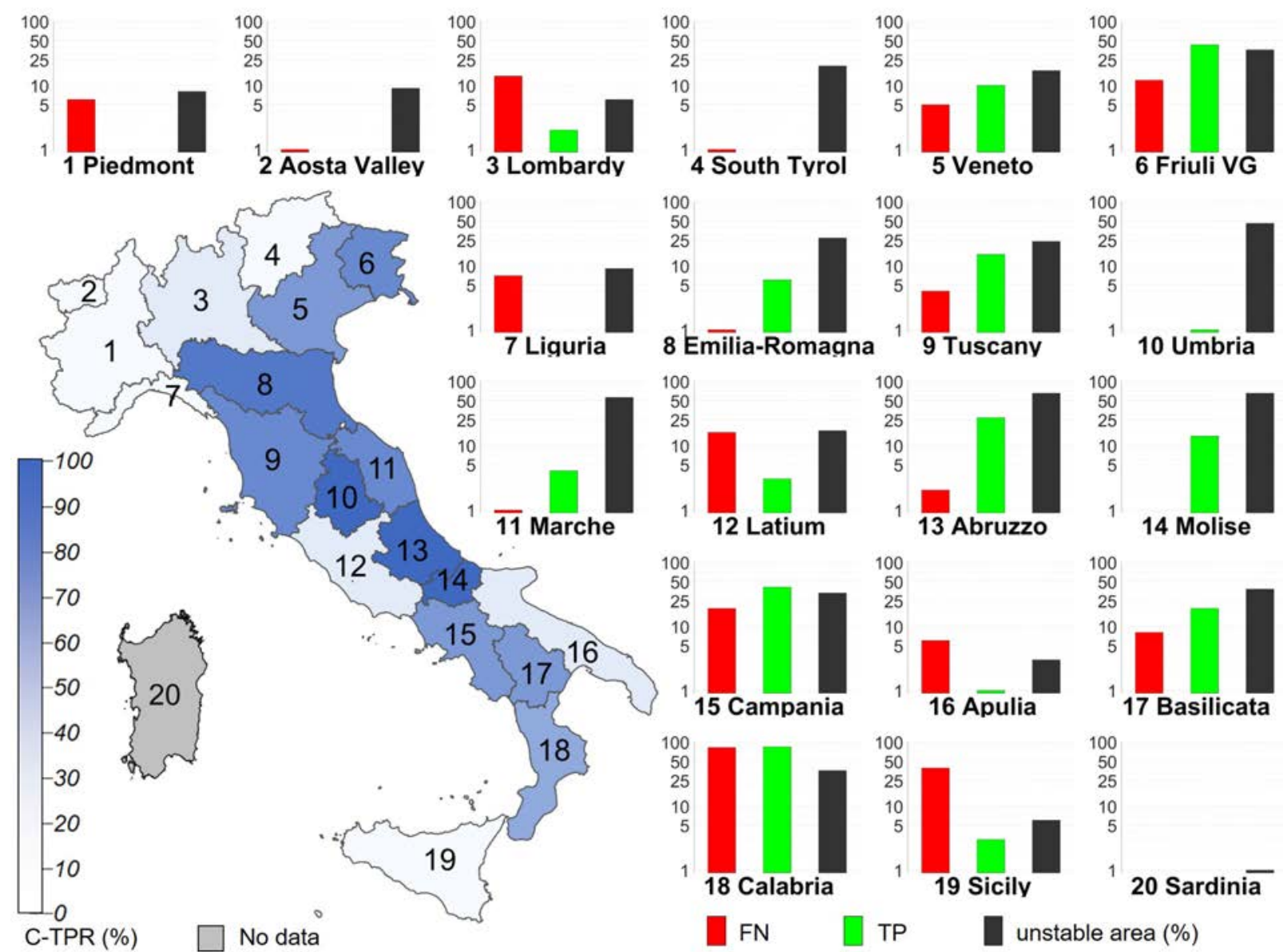

No data
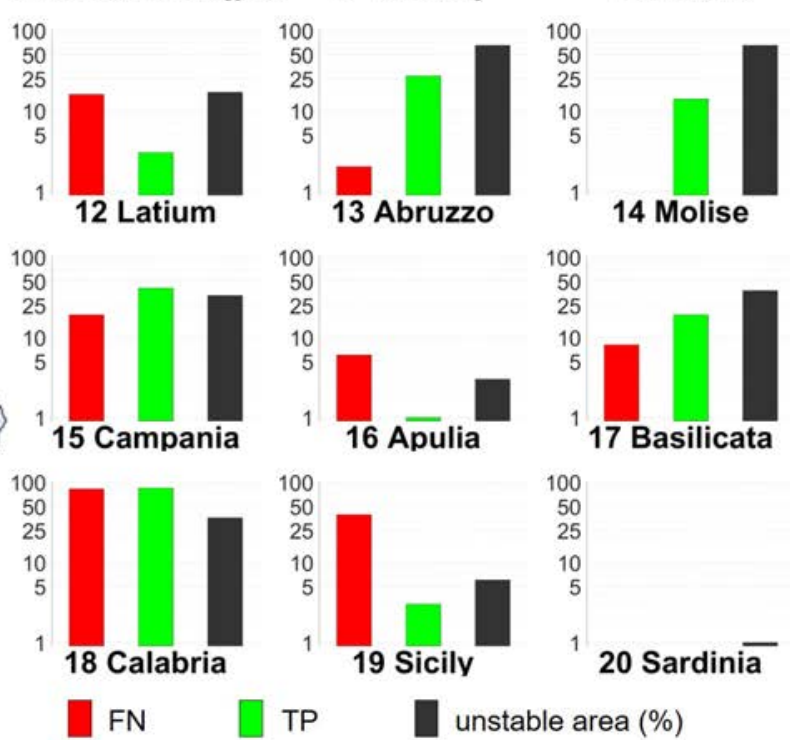

Figure 8: C-TPR value (in map), number of False Negatives and True Positives (red and green bars) per region with respect to the checking dataset. The dark bars represent the regional unstable area according to the estimated susceptibility map. 
As described in Section 3, this Check dataset is constituted by 465 EQtLs, with associated 1-to-30 km localisation error, plus 54 well georeferenced (class 5) landslides occurred before 1908. The eventual overlapping between checking landslides and unstable SUs has been evaluated to verify the correctness of the susceptibility map. In order to make the checking process reliable, a radius sized as the associated error has been taken into account around the less precisely georeferenced landslides. When more than the half of the area of the resulting circle overlapped with unstable slope units, that landslide was considered as a true positive (TP). Conversely, when the overlap was limited to less than the half of the circle area, landslides were considered as false negatives (FN). When some parts of the uncertainty circles included areas with no classification (e.g. lowlands or sea), only the portion overlapping with classified slope units was considered. Consequently, the checking TPR (C-TPR) has been calculated for every Italian region. On the basis of the susceptibility map, also the regional percentage of unstable territory has been computed. As a result, in most of the Italian regions the number of TP was higher than FN, although not all the regions counted the same number of landslides from the checking dataset. In this regard, in cases of regions with at least 15 checking landslides, the evaluation of the classification statistics is more reliable than in regions with only few landslides $(<10)$. In the latter case, C-TPR generally reached very small values. Conversely, Friuli, Veneto, Emilia-Romagna, Tuscany, Abruzzo, Molise, Campania and Basilicata show very good performances (C-TPR $\geq 70 \%)$ and a high number of checking landslides $(>14)$. In these regions, the percentage of unstable territory varies from around 20-40\% to more than 60\% in Abruzzo and Molise. Contextually, Lombardy, Latium, Sicily and Calabria show low to very low C-TPR despite the good number of checking samples. In Calabria, $36 \%$ of the regional extent has been classified as unstable, while in the other three regions the unstable territory is $<20 \%$ or $<10 \%$. Nevertheless, considering the low reached C-TPR, these percentages might have been probably underestimated.

\subsection{Predictors' importance}

PFI provided an interesting analysis of the importance that the single predictor had in order to achieve the final classification.

In Figure 9, it can be seen that the ANN mainly relies on five or six predictors while most of them provides only a small individual contribution to the classification. In particular, Geothematic and Seismic predictors play the main role: soil type (code 122), distance from seismogenic sources (123), lithology (31), distance from active faults (125) and geomorphon (10) have the highest PFI score, respectively. The first terrain predictor in order of importance is represented by the mean tangential curvature of a slope unit (code 144). Its importance, however, varied significantly among the 100 replicates. Following, all the other predictors, such as other terrain predictors and the road-related ones, account for a very little contribution to the classification and the associated PFI standard deviation is small. On the basis of the EQtLs susceptibility map, the a-posteriori distribution of the classes of 


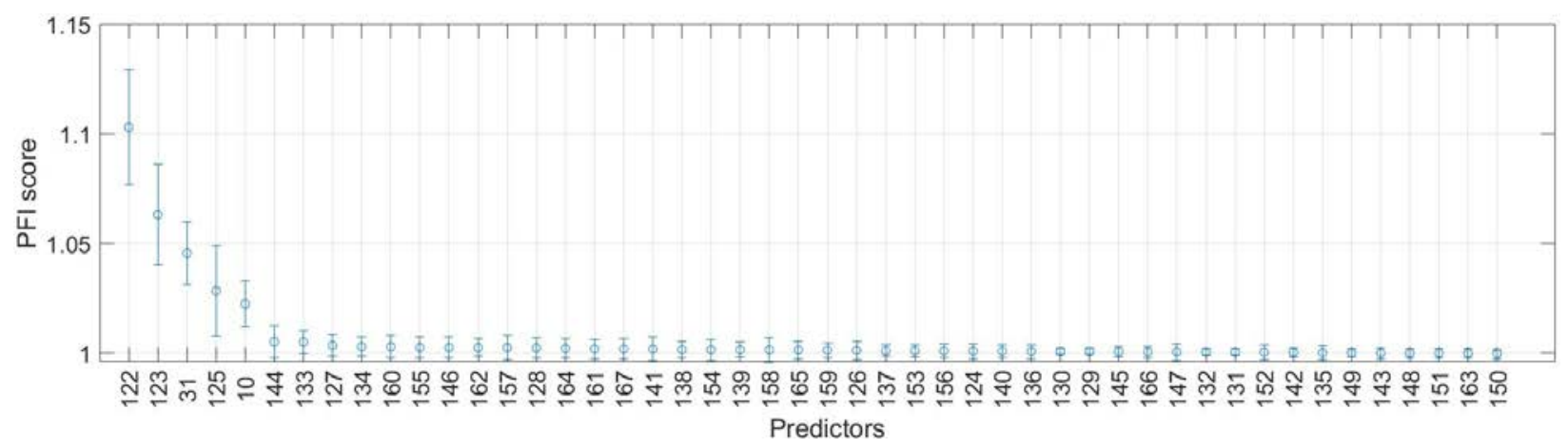

Figure 9: Resulting scheme of the Permutation Feature Importance analysis. Predictors codes are provided in Tab.1.

GEO predictors among the unstable slope units has been analysed at national level in Figure 10.

In order to make the chart clearer, only soil types with unstable slope units higher than $10 \%$ have been reported. Concerning soil types, slope units mainly covered by Dystric Cambisol resulted highly susceptible to EQtLs and the $75 \%$ of them has been classified as unstable, although they are not numerous $(<5000$ in the whole national territory). In the WRB system, "Dystric" indicates a soil with base saturation of less than 50 percent at a given depth and Dystric Cambisol is located in small parts of central and south Apennine, in seismically very active areas, which have been historically hit by strong earthquakes. Further, more than $60 \%$ of slope units composed by Rendzic Leptosol have been classified as unstable. Rendzic Leptosol is described in the WRB system as very shallow soils immediately overlying highly calcareous material and is quite frequent in Italy, particularly in central and south Apennine as well as in Friuli and Veneto regions. According to the pedological map of Europe, Chromi-calcaric Luvisol is very rare in Italy. Nevertheless, almost $50 \%$ of slope units characterised by the main presence of this type of soil has been classified as unstable. In the WRB system Chromi-calcaric Luvisol is defined as a reddish calcareous with a marked textural differentiation whose surface horizon is been depleted of clay, which accumulated more in depth. Finally, almost $40 \%$ of Lithic Leptosol slope units resulted susceptible to EQtLs. This soil type is very shallow and presents continuous hard rock within $10 \mathrm{~cm}$ from the soil surface (Tab.3). In Italy, its occurrence is limited to central Apennine, between Latium and Abruzzo, and in Sicily island. Concerning lithology, $75 \%$ of slope units mainly constituted by chaotic sedimentary complexes and $50 \%$ of those composed by marls have been classified as unstable. The first lithology is composed of sandstones (also turbiditic) and clays, locally with evaporites and subordinately limestones. It is mainly spread in central Italy, along the eastern side of the Apennine chain. The second type of rock is spread in central Italy and in the north-west. Successively, 25-40\% of arenaceous and limestone slope units resulted susceptible to EQtLs. Arenaceous formations crop out all over the Italian territory, from north-west to south and islands, mainly in mountain areas. Limestones are spread in central Italy, in those regions that were recently hit by strong earthquakes such 

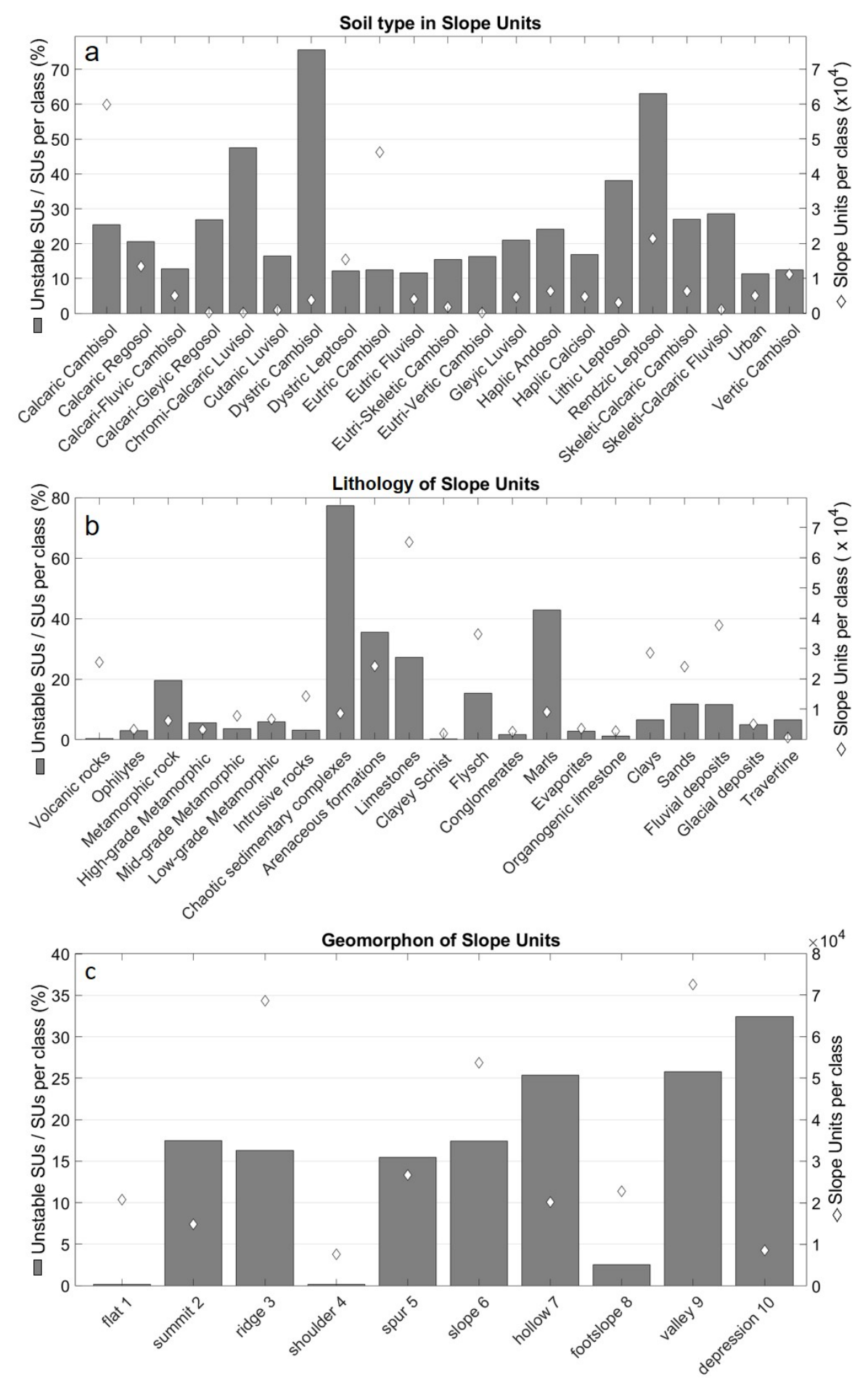

Figure 10: Distribution of slope units among the three geothemathic variables classes: bars refer to the percentage of unstable slope units out the total number of slope units, per class; diamonds indicate the total number of slope units, per class. a) refer to soil type classes.In order to make the chart clearer, only soil types with unstable slope units higher than $10 \%$ have been reported. b) refer to lithology classes and c) to geomorphon classes. 
as Umbria and Abruzzo, as well in the southern part of the Alps and along the coasts of south Italy. Finally, metamorphic rocks, mainly granitoid gneiss, whose almost $20 \%$ of slope units is considered unstable, are less spread than previous lithologies. In particular, they crop out in the northern part of the Alps and in small parts of Calabria and Sicily regions. Concerning the slope morphology, valley and concave slope units interestingly resulted to be relatively more unstable than slope units located in other parts of the slope. In detail, the 25-35\% of hollow, valley and depression slope units, has been classified as unstable against the $15-20 \%$ of summit, ridge, spur and slope classes. Finally, slope units which are linked with flat areas, such as flat, shoulder and footslope, are generally stable.

PFI provided an analysis of importance of every single predictor and indicated that Geothematicand Seismic predictors play the key role for the classification between stable and unstable slope units. It also resulted that most of the selected predictors have an almost not relevant importance. Nevertheless, when grouped, the small contribution of the less important predictors may become significant. In this paragraph, an analysis of how the classification performance changes varying the combination of groups of predictors used by the ANN is provided. Predictors have been grouped as Terrain, Seismic, Geo (i.e. Geothematic), Hydrological and Roads (Anthropic) as described in Section 3. All possible combinations made up of a variable number of groups have been taken into account (one group at a time up to all five groups together). For each of the possible combinations among these groups, the ANN has been run 20 times and the related AUCs have been calculated. Figure 11 shows the box plot of the AUC values distribution among the 20 replicates and for all the possible combinations of predictors groups.

Combinations are ordered by the medians of the AUC distributions. The background color varies according to the quartiles of the distribution of the median AUCs calculated over the 20 replicas per combination. The median quartiles are at AUC values of 0.84, 0.88 and 0.89. Lower performances (AUCs lower than the first quartile, AUC $<0.84$ ) are generally achieved with only one or two groups, or with 3-groups combinations that contain Hydrology and Roads but not Geo. Good performances (AUC values between the first and third quartile: AUC between 0.84 and 0.89 ) are achieved with all the 2-groups combinations that include Geo. In this regard, Geo+Seismic performs the best. Also combinations with three or four groups achieve good performances. Finally, those combinations of predictors groups whose AUC is entirely included in the dark red band (AUC values greater than the third quartile: AUC>0.89) can be considered as the best performing ones. Among these, two 3-groups' combinations are listed,

1. Geo+Seismic+Road

2. Geo+Seismic+Terrain

three 4-groups' combinations:

1. Geo+Seismic+Terrain+Hydrology 


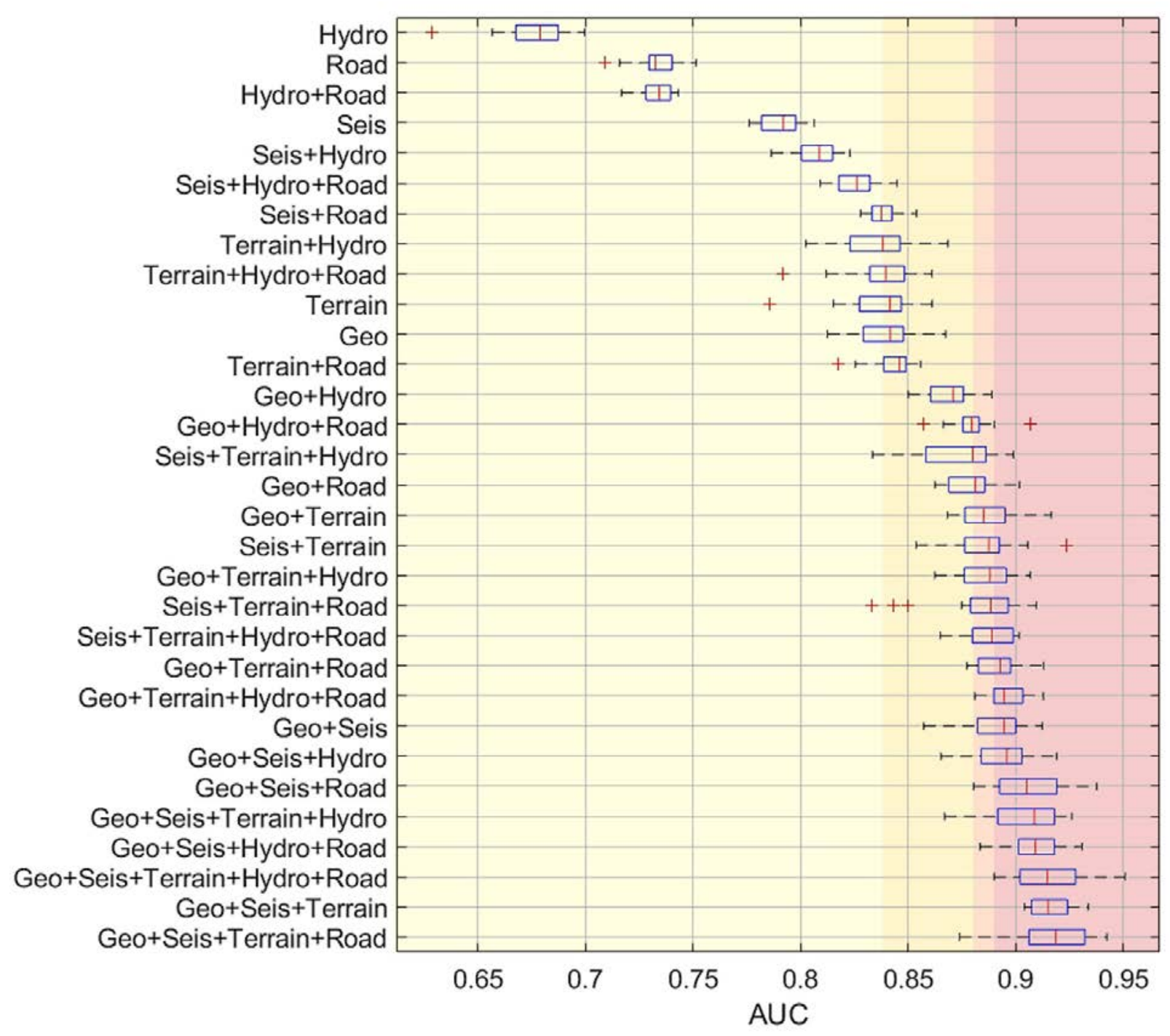

Figure 11: Box plot of the AUC distribution among 20 replicates and for all the combinations of predictors groups. Combinations are ordered by the medians of the AUC distributions. The background color varies according to the quartiles of the distribution of the median AUCs calculated over the 20 replicates per combination. The median quartiles are at AUC values of $0.84,0.88$ and 0.89 . 


\section{Geo+Seismic+Hydrology+Road}

3. Geo+Seismic+Terrain+Road

and the sole combination with all five groups. From the analysis of the best performing combinations, it is clear as Geo and Seismic predictors must be both considered in order to achieve median AUC higher than 0.89, and that at least another group is also needed. The importance of Geo (i.e. lithology, soil type and geomorphon of slope units) and Seismic (i.e. distances from active faults and seismogenic sources) predictors was previously indicated also by the PFI analysis. Nevertheless, what and how many predictors groups are needed beside Geo and Seismic was not straightforward. Related to this, on the basis of the interquartile range and the median of AUC values, Geo+Seismic+Terrain+Road and Geo+Seismic+Terrain seem to perform slightly better than all the other combinations.

Figure 12 represents a heatmap of the mean AUC value obtained by adding one of the five groups of predictors to each of all their possible combinations.

Each row contains one of the possible combinations and are sorted from top to bottom by the increasing number of groups. In each column, one of the five groups is present. The mean AUC obtained after 20 ANN replicates considering the combination in row and the adding of the group in column is reported in each cell of the heatmap. "Null" row and column respectively indicate that none of the possible combinations has been considered and that no groups have been added. Figure 12 (heatmap) confirms what has been previously seen in Fig.11 that the higher is the number of groups within a combination, the higher is the performance. Nevertheless, not all the groups have the same effect. When the classification has been carried out taking only one group at time (first row on the top), Terrain and Geo performed the best, with mean $\mathrm{AUC}=0.84$, and significantly better than Seismic (mean $\mathrm{AUC}=0.79)$ although some of the Seismic features resulted among the most important in the full model PFI analysis. Nevertheless, Terrain+Seismic reaches AUC $>0.9$ only when Geo is added while, conversely, Geo+Seismic reaches AUC $>0.9$ also with Roads appearing that, when combined with Geo, Seismic provides a bigger contribution than Terrain. This led to infer that Terrain and Geo groups might bring partially overlapping information and that those brought by Seismic better combine with Geo than with Terrain features. In general, when the Geo group is added to whatever combination (second column from the left in Fig.12), the mean AUC reaches 0.9 in seven cases and it never goes below 0.8. This means that the Geo predictors have a high importance for the ANN and their presence ensures very good performances, whatever other group is added to the combination. Similarly, Seismic predictors allow to reach mean AUC $\geq 0.9$ when added to six different combinations. Further, when they are present, performance decreases below 0.8 only in one case and the combination Geo+Seismic achieves AUC $=0.89$. Conversely to Geo and Seismic, only four combinations that include Hydrological predictors allow to achieve a mean AUC of at least 0.9 and, in all these cases, Geo is present. Also, two combinations that include Hydrological predictors do not reach $\mathrm{AUC}=0.8$. Finally, five combinations containing Roads and five 


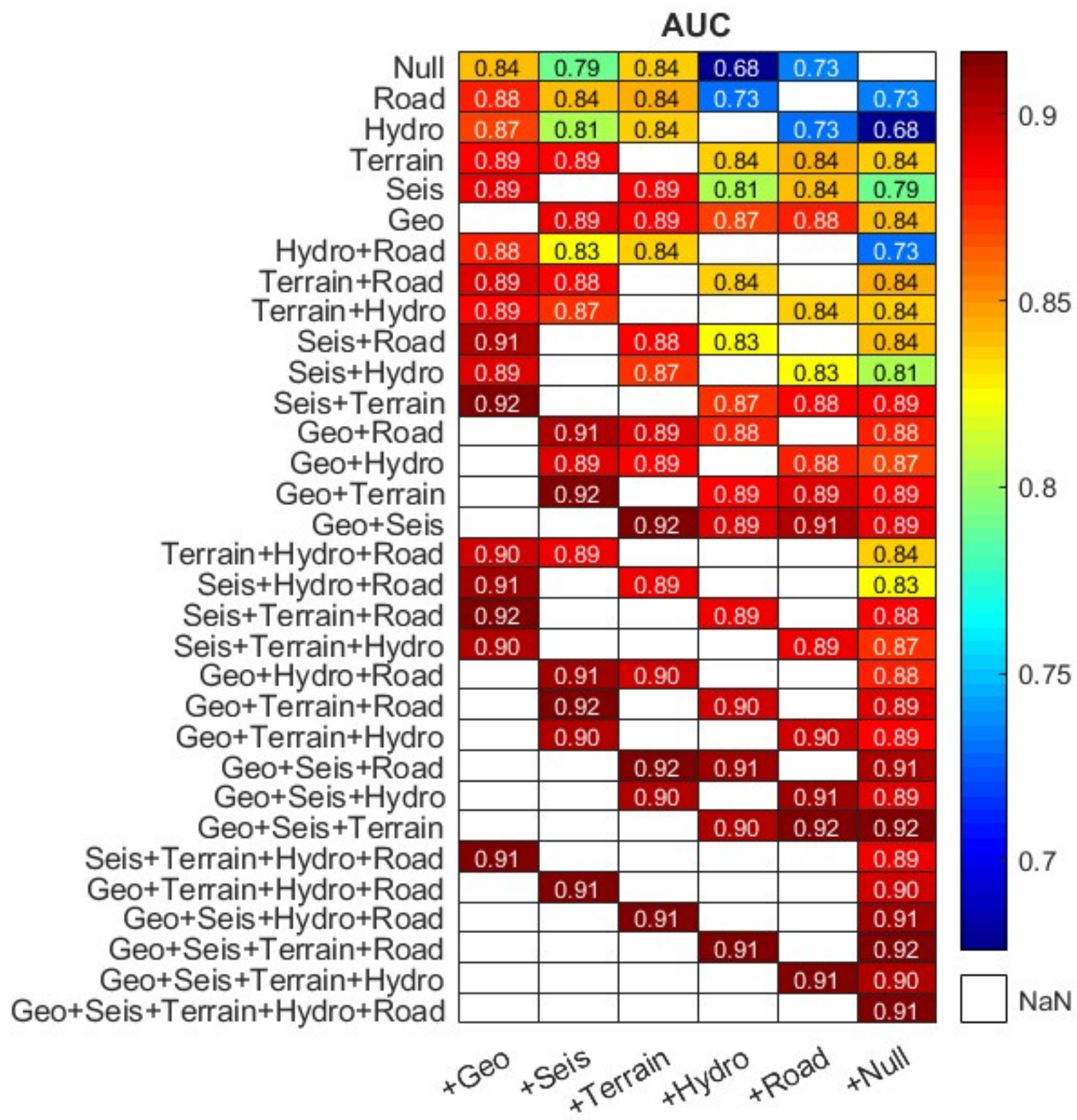

Figure 12: Heatmap of the mean AUC values after 20 replicates for all the combinations of predictors groups. Combinations are obtained by adding the group in column to the combination in row. Combinations in rows are sorted from top to bottom by the increasing number of groups. In each column, one of the five groups is present. "Null" row and column respectively indicate that none of the possible combinations has been considered and that no groups have been added. 
combinations containing Terrain reach mean $\mathrm{AUC}=0.9$. This means that the probability to reach very good performance by a combination that contains Road-related predictors is the same as a combination that includes terrain predictors. However, when Roads is added to Geo and Seismic, AUC arrives to 0.91 viceversa, when Terrain is added to Geo and Seismic, AUC averagely arrives to 0.92. Adding Roads to Geo+Seismic+Terrain brings a contribution lower than 0.01 while, adding Hydrology, performance decreases to 0.90. Besides, 0.92 is the highest mean AUC reached by the ANN and is due to the main contribution of Geo and, successively, Seismic information. Terrain predictors would have a much higher importance, when grouped, than that resulted by the single predictors analysis. But its information might be partially provided also by Geo predictors and, when combined with other groups, it accounts for slope units variability less than Geo group, ending to provide only +0.03 to the combination Geo+Seismic. From this analysis, the key role of Geo and Seismic predictors is confirmed and emphasized. Also, a significant contribution of Terrain has been proven. At the same time, the non-significance of distance to rivers as a predictor for EQtLs susceptibility is resulted and a not ignorable contribution to improve the classification performance is given by the presence of roads. Finally, concerning what can be selected as the most performing combination among all the possible and tested ones, it should be noted that the differences between the mean AUC values for the three best median AUC combinations, that are, Geo+Seismic+Terrain, Geo+Seismic+Terrain+Road and Geo+Seismic+Terrain+Road+Hydro, are not statistically significant ( $p$-value $=0.86$ with one-way ANOVA test).

\section{Discussions}

The sections below are meant to provide the reader with an overview of strengths and potential weaknesses of the modeling protocol we implemented, these discussed both from the data as well as the modeling strategy perspectives.

\subsection{Supporting arguments}

\subsubsection{Quality and completeness}

Data quality and completeness are two main features to evaluate the reliability of landslide inventories (Guzzetti et al., 2012; Tanyaş and Lombardo, 2019, 2020). Quality can be defined based on geolocalisation precision while completeness represents the extent to which an inventory includes all the landslides effectively occurred during a triggering event, e.g. earthquake in the case of EQtLs (Guzzetti et al., 2012). Both of these characteristics directly affect the reliability of a landslide susceptibility model and contribute to its accuracy (Lombardo and Mai, 2018). In this regard, the CEDIT catalogue, on which the susceptibility analysis presented here is based, exhaustively fulfils the above mentioned requirements of completeness and quality, representing a very detailed collection of information about 
earthquake-induced ground effects in Italy from 1117 A.D. to date. Concerning completeness, as described in Material and Methods paragraph, this catalogue was built through a systematic revision of historical archives and documents (for older earthquakes) and by a capillary field surveys of induced effects carried out immediately following recent earthquakes greater than Mw 4.0 (as like the Mw 4.0 Casamicciola 2017 earthquake, which induced 11 ground effects between landslides and ground cracks - (Martino et al., 2020b) - and the Mw 5.1 Montecilfone 2018 earthquake that induced 88 ground effects between landslides and ground cracks and represents the last strong earthquake that hit the Italian territory, (Martino et al., 2020a). All this makes the CEDIT an unicum in the world (Tanyas et al., 2017) since systematic inventories of historical documented earthquake-induced ground failures for an entire country have been rarely produced until now. A first attempt was provided, for example, by Youd and Hoose (1978) who reported data of about 350 localities in which several kinds of ground failures took place after 46 earthquakes that struck North California but only between 1800 and 1970. However, the fact remains that when it comes to historical or prehistoric earthquakes, data incompleteness is an unavoidable problem due to the difficulty of making the analysis of historical sources and chronicles very exhaustive. For this reason, the CEDIT database is constantly updated both with regard to historical earthquakes, e.g., the update regarding the effects produced by the Reggio and Messina 1908 earthquake on the basis of new data published by Comerci et al. (2015); Martino et al. (2020c) and, obviously, recent earthquakes. Moreover, the current trend is to exploit the power of the internet through blog or on-line repositories which can be upgraded in real time after an earthquake occurrence thereby allowing a very fast process of reporting (Petley et al., 2005; Kirschbaum et al., 2010), e.g., for the CEDIT catalogue by compiling the on-line notification form of earthquake-induced ground effect. Regarding the quality of the data collected in the CEDIT, as already presented in the Materials and Methods paragraph, a geolocalisation class is attributed to each ground effect, with an associated uncertainty ( $0 \mathrm{~m}$ in class 5 up to $30 \mathrm{~km}$ in class 1). Usually, the older the effect, the higher is the error related to its geolocalisation, since this was not possible to be attributed by the means of a GPS. Nevertheless, thanks to the above mentioned constant analysis of bibliographic sources of historical effects, an update toward class 5 was possible also for several ancient landslides. Such meticulousness in the compilation of the CEDIT allowed that the EQtLs included in the input dataset, which served to train the network, are all characterised by a geolocalisation class equal to 5 and fairly evenly distributed throughout the Italian peninsula as consequences of strong earthquakes from 1908 to 2018. Further, as reported in Material and Methods paragraph, the input dataset also well respects the CEDIT curve, calculated by Martino et al. (2014) for Italy on the basis of the Keefer curve (Keefer, 1984), and its upgrade (Rodriguez et al., 1999), making the input dataset a very reliable dataset to train the neural network. 


\subsubsection{ANN performance overview}

The ANN performance was very good. In detail, after 100 replicates mean AUC was 0.91 and the associated standard deviation was 0.01 . Considering that both positive and negative samples (i.e. slope units with and without landslides) within training, test and validation datasets changed at every replicate, the very low standard deviation is an excellent result, which demonstrates a solid stability of the network. Also the ability to distinguish between the two classes was high: averagely, TPR, namely the ability to correctly classify unstable slope units, was 0.85 while TNR, proficiency in classifying stable slope units, was 0.84 . Both metrics show standard deviation lower than 0.02 after 100 replicates confirming the robustness of the classification. In particular, the classification error plot shows low standard deviations especially for those SUs classified as extremely stable (mean susceptibility $<0.25$ ) or unstable (mean susceptibility $>0.75$ ), giving rise to a high reliability of the final susceptibility model. These outputs fulfill the aim of the work to perform a robust susceptibility analysis of earthquake triggered landslides at the national scale which, being trained on landslides distributed over more than one century and over the whole Italian territory, could serve as a basis to prioritise funds for remedial interventions at national to regional levels.

\subsubsection{EQtLs Susceptibility patterns}

The EQtLs susceptibility map of Italy obtained by the means of the neural network approach was compared with a landslide distribution map of Italy derived from the IFFI inventory. We recall here that the IFFI inventory does not focus on a specific trigger but it rather reports landslides whose genesis is linked to rainfall, earthquake, snowmelt and anthropic effects.

The comparison reveals an interesting output which regards the main distribution of earthquake-induced landslide all along a more internal portion of the Apennine Chain backbone (Figure 13).

As a result, the eastern coastal zone is less predisposed to landslide triggering due to earthquakes. On the north, along the Alps Chain, the highest susceptibility zone corresponds to the eastearn area, namely parts of Veneto and Friuli regions, where seismogenic sources are more concentrated. It is worth noting that the IFFI inventory takes only partially into account first time failures related to rock mass (i.e. falls, topplings, slidings) as their sizing is often out of the database resolution. On the contrary, the highest percentage of earthquake-induced failures inventoried in the CEDIT and located in mountain areas consists of disrupted landslides (sensu Keefer, 1984). This justifies the high susceptibility referred to the Southern Apennine backbone (i.e., Basilicata and Calabria regions) if compared with the low concentration of IFFI inventoried landslides.

As stated previously, the general purpose of the work was to provide a reliable overview of the earthquake-triggered landslide susceptibility in Italy. The average dimensions of the chosen mapping unit, i.e. $0.7 \mathrm{~km}^{2}$ slope units, provides a detailed level of spatial resolution to the susceptibility map but cannot be used for projecting applications or municipality planning. 


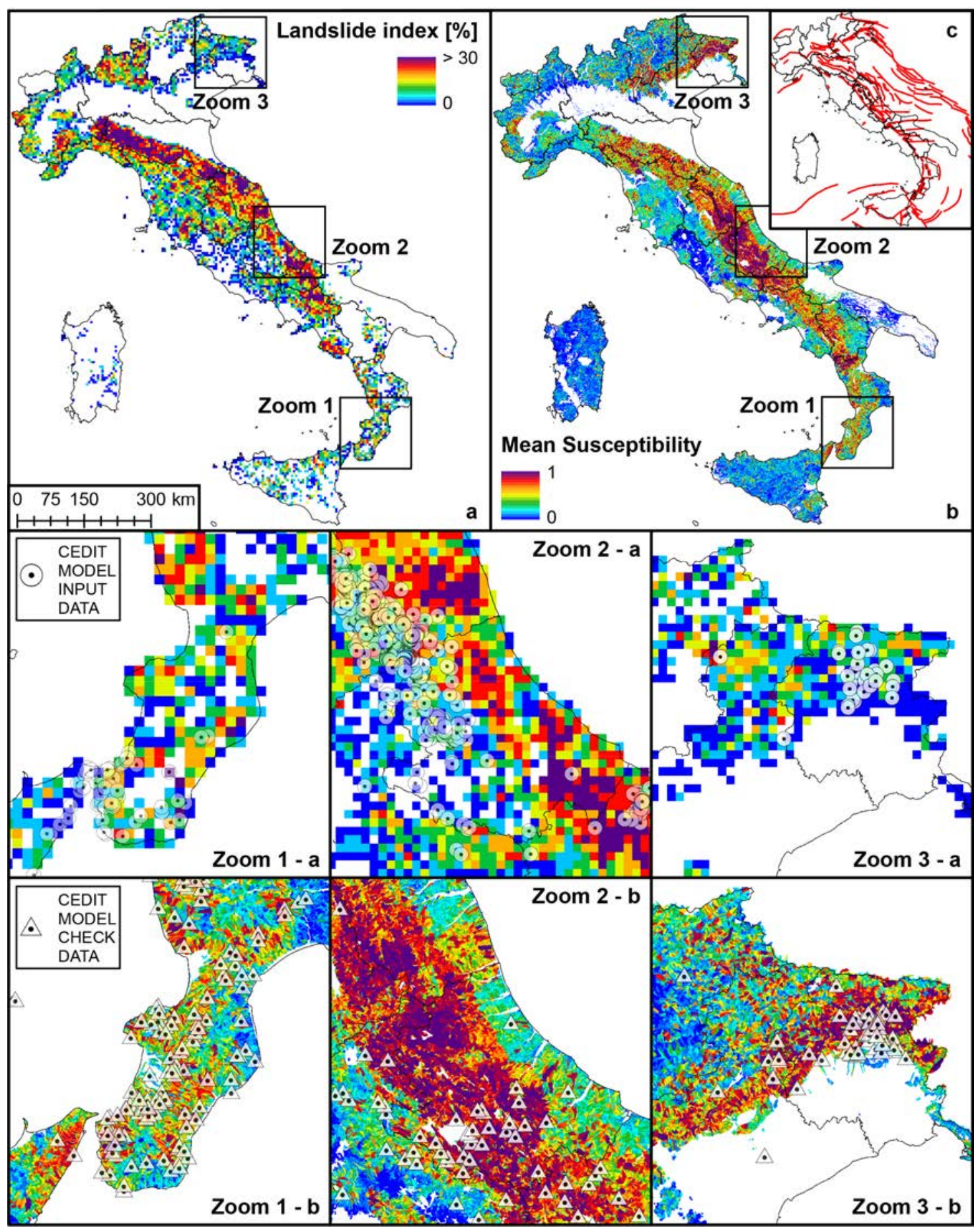

Figure 13: a) Map of landslide density derived by the IFFI inventory. Each pixel is 5x5 km. b) Earthquake-triggered susceptibility map of Italy produced in this study. Zooms of the maps in a) and in b) are shown in the upper and the lower bands, respectively. Circles represent the landslides of the input dataset used in the ANN training process. Triangles represent the landslides of the checking dataset used for an ex-post evaluation of the susceptibility map. 
Nevertheless, the here obtained map represents an accurate model when observed at regional scale and clearly identifies what are the more susceptible areas with respect to the more stable ones. In those regions where the a-posteriori model check reaches high performance (C-TPR $>70 \%$ in Fig.8), such as Veneto, Tuscany, Friuli, Abruzzo, Emilia-Romagna, Molise, Campania and Basilicata regions, the produced EQtLs susceptibility map can be taken as a reliable instrument to drive the decision makers toward appropriate funding management, i.e. in order to provide priority lists of local interventions. The necessity of such instruments is highlighted by the comparison between the overall landslides density map and the here presented EQtLs susceptibility map, which clearly indicates that areas highly susceptible to earthquake-triggered landslides could be not taken into account in frame of landslide mitigation National funds since not necessarily exposed to an high generic landslide hazard, e.g. rainfall-induced. Contextually, in these areas, the likely dedicated funds for earthquake risk mitigation might tend to be used primarily for building reinforcement, keeping on ignoring the significant slope stability matter demonstrated with this study. Keeping this in mind, authors are aware that local administrations require a more local spatial resolution in cartography support, due to the needing to adopt such instruments in design applications and seismic microzonation. In this regard, the methodology adopted for this study is suitable for rescaling and can be adopted to perform local and more detailed susceptibility analysis in those areas classified as highly unstable. In detail, the trained network can be applied to selected areas partitioned with smaller mapping units, such as pixels or more segmented slope units. Furthemore, providing higher resolution predictors dataset (e.g. high-resolution DTM, georeferenced roadcuts information, bigger scale geological maps), which are not available for the whole national territory, the same ANN can be retrained in order to learn how to model a detailed variability of terrain properties, which consequently dilutes when analysis are performed at smaller scale.

\subsubsection{Predictors' role}

One of the advantages of using an ANN approach, as mentioned in Introduction, is its ability to handle multicollinearity among variables, which allowed the authors to consider a large number of potential predictors of EQtLs and to investigate less discussed variables which relations could not be known a priori. Beside these advantages and the remarkable results in terms of performance stability and reliability, ANNs commonly suffer difficulty in model interpretation. In order to provide to the reader an indication about variables importance, a permutation feature analysis has been performed and the ANN performances were tested with different predictors groups combinations. From the PFI analysis resulted that soil type, distance from seismogenic sources, lithology, distance from active faults and geomorphon are the most important predictors for the network and, as consequence, for the good result of the classification between stable and unstable slope units. As one can expect from an application on earthquake-triggered landslides, distance from seismogenic sources and distance from active faults (second and fourth predictors in order of importance) played a key role in the 
classification, demonstrating to well represent the slope units variability due to seismic predictors. In this regard, the seismogenic source represents the portion of a fault that is more likely to enucleate a Mw>5.5 earthquake (Basili et al., 2008; DISS-Working-Group, 2018). Nevertheless, landslides can occur even along the tip portions of a fault, after $\mathrm{Mw}<5.5$ seismic events or in correspondence of secondary segments, therefore distances from both source and fault line have been considered. As reported in Material and Methods paragraph, the choice of these predictors was done in order to avoid the underestimation of the resulting susceptibility in those areas where high ground acceleration is not expected by the national PGA model or where no inventoried landslides are available since significant earthquakes have not occurred from 1908. Taking into account seismogenic sources and active faults, the susceptibility analysis presented in this study resulted in being an inclusive model that is not bound to some specific seismic events and can be applied to the whole National territory accounting for a more local variability than that provided by the national PGA. Soil type resulted to be the most important predictor from the PFI analysis. Statistically speaking, this may be partially due to the fact that slope units have been characterised on the basis of 91 different soil types, giving rise to an high, detailed, pedological variability. This represents an impressive quantity of data for the ANN to take useful information from in order to perform the classification. Related to this, lithology and geomorphon, which only count 21 and 10 classes respectively, might have provided lesser, albeit meaningful, information, that result as third and fifth more important predictors, respectively, among all the considered ones. In percentage, the most unstable soil categories resulted in poorly developed pedotypes, generally thin, and derived from the alteration of rocky or highly calcareous bedrocks. This result is in line with what resulted from the analysis of the instability percentage per lithology class, which shows as calcareous and arenaceous formations, beside clayer and marly lithologies, are largely present within the unstable slope units. These results reflect the high abundance of disrupted failures that affect rock masses during an earthquake, as like rock fall, which also represents the most numerous landslide type in the Input dataset (Fig.2).

It is particularly relevant that slope units with prevalent Chromi-calcaric Luvisol, although they are very rare in Italy, are in percentage rather unstable. They are located in Veneto region, within a restricted area quite close to some few landslides that occurred in consequence of an earthquake that struck the region in 1936 and had an epicentre $60 \mathrm{~km}$ away. In this case, a clustering effect can not be ruled out: it may have been the earthquake, with consequent EQtLs, to occur in correspondence of areas with Chromi-calcaric Luvisol rather than the presence of this soil favouring the trigger of EQtLs. Concerning geomorphon, its importance may be linked to several aspects. Intuitively, slope morphology is strictly correlated with the probability of landslides occurrence. Related to this, geomorphon classes could properly represent the most important morphological features of a slope, accounting for the contribution given by the terrain predictors to the ANN, which did not result as important as one could expect. In particular, from our analysis it resulted that hollow, valley and depression slope units have been classified more frequently unstable than summit and 
ridge areas. This aspect can be partially linked with the presence of roads in the lower part of the valley sides, as it occurs in many mountainous regions of Italy. Martino et al. (2019) found out that the presence of road cuts at the bottom of deeply incised V-shaped valleys played a conditioning role to the spatial distribution of EQtLs triggered in 2016 in Central Italy higher than road cuts located elsewhere.

The tests shown in Figures 11 and 12, allowed to evaluate the importance of the different groups of predictors and was particularly useful to investigate the contribution given by those predictors that, taken singularly, did not show a significant importance in the PFI analysis, since the sum of small contributions can result in a higher importance when predictors are grouped. In this regard, from both PFI and group combinations analysis, Geothematic and Seismic groups resulted in being the most important predictors, as largely supported in literature by other susceptibility analyses of EQtLs (Fan et al., 2019; Lombardo et al., 2019; Tanyaş et al., 2019).

In particular, these two groups achieve $\mathrm{AUC}=0.89$ if combined with each other. But they must include at least another group in order to reach AUC higher than 0.9. Related to this, Terrain and Hydrology were probably expected to assume a much higher weight whereas Terrain provides only +0.03 to the mean AUC value reached by Geo+Seismic while, adding also Hydrology, the performance slightly decreases. This leads to conclude that Geothematic predictors can likely fulfill almost totally the information offered by the terrain features and can ensure the best performance with a further contribution deriving from Seismic and, limitedly, Terrain groups. From all the analyses then, Hydrology has never resulted in any importance, ledding to conclude that its role is non-significant or that the same information is already carried by other predictors. Finally, the contribution of the distance from roads to the classification performance resulted to be not negligible. In particular, the ANN runned taking only the predictors group of Road was able to reach an AUC equal to 0.74. As introduced before, cases of earthquake-triggered landslides that mostly occurred along slopes which have been modified by road cuts, are widely documented in literature (Keefer et al., 2006; Delgado et al., 2015; Martino et al., 2019). In this context, despite the role of roadcuts in favoring EQtLs occurrence is probably more appreciable in applications on small study areas, this study also contributes to the ongoing debate drawing attention to the potential importance of this predictor although the analysis was performed at a National scale.

\subsection{Opposing arguments}

\subsubsection{Validation routine through the Check data}

The Italian EQtLs susceptibility map, albeit resulted from a robust iterative trainingvalidation-test procedure, shows heterogeneous results between different regions from the comparison with the Check EQtLs dataset, which was not used to train the ANN. This can be partially due to a low number of check landslides in regions like Piedimont, Aosta Valley, Liguria and Apulia although in other regions with a significant number of check landslides 
the Checking TPR was still not satisfactory (Figure 8). In particular, Calabria and Sicily show low C-TPR in spite of a high number of checking landslides. A reason for this could be that, as shown in zoom 1 in Figure 13, the Input landslides from which the ANN was trained are concentrated in the area of the Strait among these two regions while the checking EQtLs are more spread over the regional territory. This may have led to a too-low-generalised training of the network. Further, the exact location of seismogenic sources in Calabria is an argument of debate in the scientific community. Considering the importance assumed by the Seismic predictors in our analysis, their potential location's uncertainty can significantly affect the accuracy of our model.

\subsubsection{Predictors associated to tectonic elements}

As it regards the landslide location with respect to the seismogenic sources, here we only took into account the distance computed with respect to the fault plane albeit fault dimension (i.e. length) could be also considered since it is related to the expected magnitude for a certain return time. As a consequence, in the present analysis, if a SU is located between two faults, one could observe that a landslide might be triggered by the farthest one, if longer and able to generate a stronger earthquake. Nevertheless, it has to be noted that fault length could be relevant if the susceptibility analysis was aimed at building a scenario prediction while it should play a secondary role for the ANN training phase. Indeed, fault length is the same for the whole distribution of landslides triggered by an earthquake sourced from a given fault, causing that the landslides distribution used to train the network is not directly related to the length of the triggering source but can be rather considered an effect of the specific seismic action of the event, i.e. its magnitude. Therefore, to take into account the fault length as a proxy parameter for landsliding, a return time should be defined in order to associate a fixed magnitude to each seismogenic source, derive the related local action through the seismic attenuation law and, as a consequence, generate a national susceptibility model for a given earthquake magnitude scenario. Although of extreme importance and potentiality, this kind of scenario-based model was not within the aims of this study and, moreover, authors consider that such a more sophisticated and detailed analysis is crucial only for restricted areas, which could be realistically individuated on the basis of a reliable generic and scenario-free model such that provided by the EQtLs susceptibility map here provided. It also must be noted that the here presented susceptibility analysis partially integrates an indirect scenario-related approach, since the great majority of the EQtLs included in the Input dataset (1122 out of 1545) has been triggered by earthquakes with magnitude constrained in a small interval, i.e. $5.5-6.5 \mathrm{M}_{W}$.

\subsubsection{Model interpretability}

Concerning the adopted methods, it has been reported that ANN approaches are suitable for modelling complex relations among variables and, on the other hand, may suffer some difficulty in model interpretability. According to such a consideration, the PFI and the 

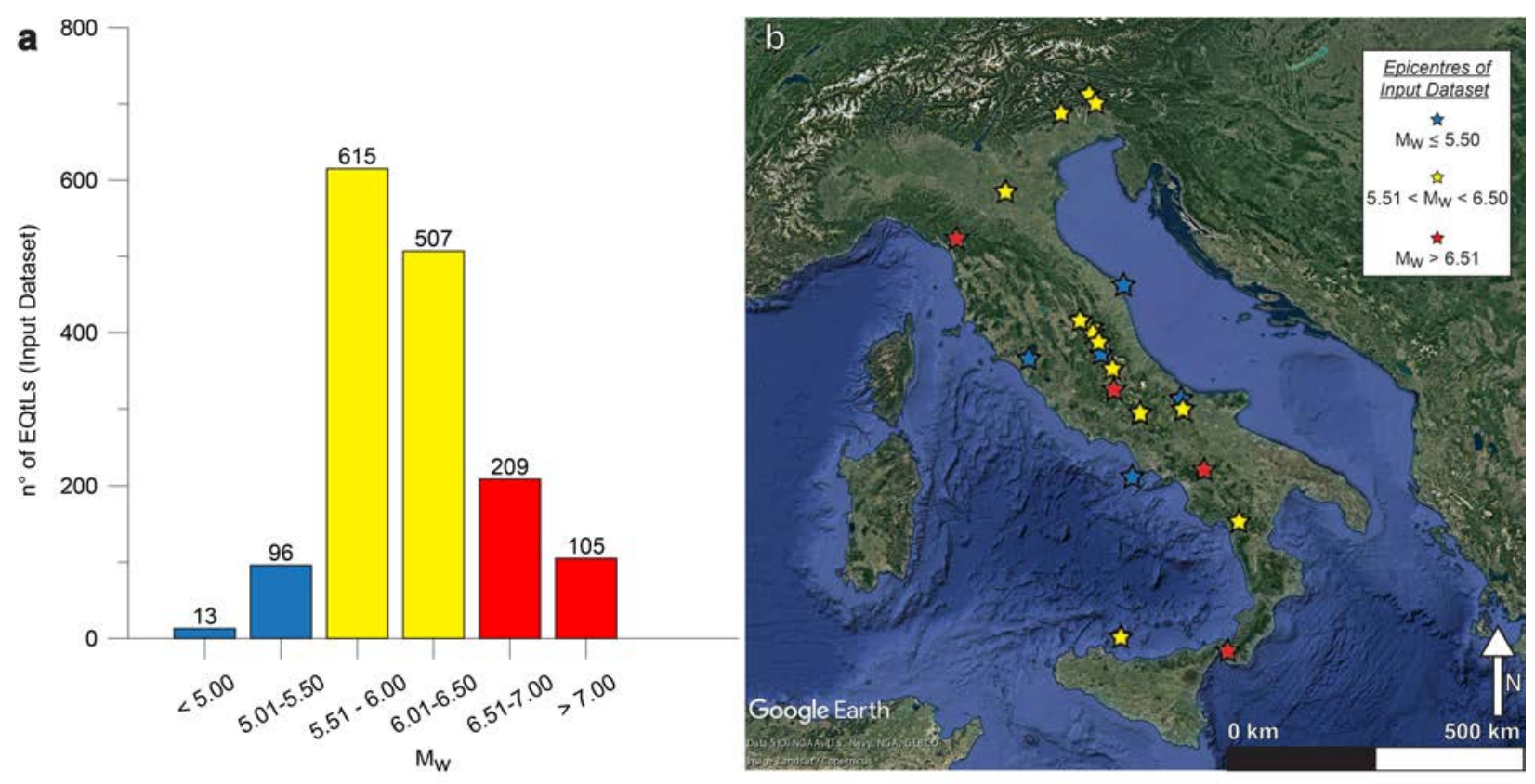

Figure 14: a) Bar chart illustrating the number of EQtLs, belonging to Input dataset, as a function of the $\mathrm{M}_{W}$ of the earthquake that triggered them; b) epicentres of earthquake that triggered the EQtLs of the Input dataset coloured as a function of their $\mathrm{M}_{W}$ class.

predictors-group analysis have been performed in order to provide the reader with instruments to interpret the obtained results. In the first case an estimation of the importance of the single predictor in the full model has been computed while, in the second, the contribution in terms of information supplied by each predictors-group has been investigated. Contextually to what previously discussed on the role of Road predictors group, the difficulty to infer deeper conclusions about the role played by local variables, such as the presence of roads, in favouring EQtLs is mainly due to the chosen scale of application, which necessarily required the availability of consistent information all over the whole national territory. Further investigations at a more detailed scale are thus required in this field. Finally, difficulty rises when landslides triggered by historical earthquakes are considered, since the GIS layer of the road network of the whole Italian territory has been produced only recently and on the basis of the nowadays viability pattern.

\section{Concluding remarks}

This study represents the first example of susceptibility analysis to Earthquake-triggered Landslides built at the national scale in Italy by using an ANN approach. At this aim, we exploited the CEDIT catalogue, which encompasses ground effects triggered by strong earthquakes starting from the $12^{\text {th }}$ century. And, we implemented an ANN at the Slope Unit scale featuring predictors that take into account predisposing factors of morphological, 
lithological and seismotectonic characteristic of the Italian territory. To train the ANN, a sub-dataset made of 1545 EQtLs related to the more recent and strong earthquakes (i.e., from 1908 to date) was extracted from CEDIT. This subset is the most accurate in terms of geolocalisation of the effects. Therefore it provided a very robust and reliable input dataset in terms of completeness and data quality.

The ANN highly performed in predicting the occurrence of EQtLs. This was actually tested twice. Once by using the 1545 EQtLs mentioned above (by replicating the ANN validation-test cycle 100 times) but also by using an additional and external dataset composed of 465 EQtLs, which were not inserted in the model building phase due to a lower geolocolation accuracy. This ex-post verification confirmed the overall suitability of our ANN analytical protocol.

In particular, the ANN was optimized and trained for the classification of Slope Units in terms of susceptibility to earthquake-triggered landslides, on the basis of 167 predictors. The performances of the ANN have been evaluated carrying out 100 training on independent datasets assess its robustness. The ANN showed remarkable general performances with regard to the overall capability to distinguish between the two classes with an average value of the AUC equal to 0.91 and a standard deviation of 0.01 over the 100 training replicates. Establishing a threshold of classification equal to a probability of 0.5 we obtained a mean True Positive Rate of $85 \%$ and a True Negative Rate of $84 \%$. For both parameters a limited value of the standard deviation, equal to $2 \%$ allows to estimate the robustness of the model as optimal.

The analysis shows that a large portion of the Italian national territory is highly prone to earthquake-triggered landslides. This is especially the case throughout the Apennine arc, with a more marked predisposition in the central-northern sector, where high susceptibility values are associated to more than $50 \%$ of the local territory (Abruzzo, Marche, Molise, Umbria). The same is valid for $\sim 25 \%$ of Tuscany, Emilia-Romagna, Campania and Basilicata.

Furthermore, the Alpine arc is more susceptible in its eastern sector where high susceptibility values are associated to approximately $25 \%$ of the territory of Friuli region.

As for the north-western regions, Sicily, Sardinia and most of Lazio and Puglia regions appear to be quite stable with minor percentages of the territory characterized by susceptible slopes.

As regards future improvements we envision for this study, two main extensions to the current modeling framework should be pursued. The first consists of scaling down the model to a greater spatial resolution. As the model is, the SU size are extremely detailed even for a regional or provincial scale assessment. Nevertheless, the resolution of these mapping units is still far from the requirements for planning purposes, or for seismic microzonation studies at a municipal scale. To downscale our model to the typical resolution of microzonation studies, a similar neural network can be trained on even smaller slope units. This will largely increase the total number of slope units, thus also increasing the overall computational time. To cope with this new dimensionality of the dataset, we envision to focus on specific areas rather 
than focusing on the whole Italian territory. For instance, we could model the Apennines' sector in central Italy and make inference for a specific sub-region of particular interest.

This initial extension to the protocol presented here will also enable a second and equally relevant research topic. In fact, physically-based models are already available to asses the EQtLs susceptibility at very fine spatial scales. However, they typically lack the ability to be upscaled to very large regions. This situation has lead to significant differences in the geoscientific community, where small portion of the landscape are generally analysed via physically-based models and larger ones are analysed via statistically-based models. This in turn implies that the two scales and associated modeling estimates are not easily comparable. For this reason, we envision a comparative extension of the present study where a much finer partition of the Italian landscape will be achieved, only to focus the analyses on a data-rich sub-sector where our ANN and a suite of physically-based models will be run. As a result, we could compare the two outputs and investigate potential differences, both in terms of strength and weaknesses, between each modeling routine.

\section{References}

Alfaro, P., Delgado, J., Tortosa, F. G., Giner, J., Lenti, L., Casado, C. L., Martino, S. and Mugnozza, G. S. (2012) The role of near-field interaction between seismic waves and slope on the triggering of a rockslide at Lorca (SE Spain). Nat. Hazards Earth Syst. Sci.) 12, 3631-3643.

Althuwaynee, O. F., Pradhan, B., Park, H.-J. and Lee, J. H. (2014) A novel ensemble decision tree-based CHi-squared Automatic Interaction Detection (CHAID) and multivariate logistic regression models in landslide susceptibility mapping. Landslides 11(6), 10631078.

Alvioli, M., Marchesini, I., Reichenbach, P., Rossi, M., Ardizzone, F., Fiorucci, F. and Guzzetti, F. (2016) Automatic delineation of geomorphological slope units with r.slopeunits v1.0 and their optimization for landslide susceptibility modeling. Geoscientific Model Development 9(11), 3975-3991.

Alviolicor, M., Guzzetti, F. and Marchesini, I. (2020) Parameter-free delineation of slope units and terrain subdivision of Italy. Geomorphology p. 107124.

Amato, G., Eisank, C., Castro-Camilo, D. and Lombardo, L. (2019) Accounting for covariate distributions in slope-unit-based landslide susceptibility models. a case study in the alpine environment. Engineering Geology 260, In print.

Avolio, M. V., Di Gregorio, S., Lupiano, V. and Mazzanti, P. (2013) SCIDDICA-SS 3: a new version of cellular automata model for simulating fast moving landslides. The Journal of Supercomputing 65(2), 682-696. 
Ayalew, L. and Yamagishi, H. (2005) The application of GIS-based logistic regression for landslide susceptibility mapping in the Kakuda-Yahiko Mountains, Central Japan. Geomorphology 65(1), 15-31.

Basili, R., Valensise, G., Vannoli, P., Burrato, P., Fracassi, U., Mariano, S., Tiberti, M. M. and Boschi, E. (2008) The Database of Individual Seismogenic Sources (DISS), version 3: Summarizing 20 years of research on Italy's earthquake geology. Tectonophysics 453(1), 20-43. Earthquake Geology: Methods and Applications.

Beven, K. and Kirkby, M. J. (1979) A physically based, variable contributing area model of basin hydrology/Un modèle à base physique de zone d'appel variable de l'hydrologie du bassin versant. Hydrological Sciences Journal 24(1), 43-69.

Bird, J. F. and Bommer, J. J. (2004) Earthquake losses due to ground failure. Engineering geology $75(2), 147-179$.

Bommer, J. J. and Rodriguez, C. E. (2002) Earthquake-induced landslides in Central America. Engineering Geology 63(3-4), 189-220.

Bonham-Carter, G. F. (1989) Weights of evidence modeling: a new approach to mapping mineral potential. Statistical applications in the earth sciences pp. 171-183.

Bout, B., Lombardo, L., van Westen, C. and Jetten, V. (2018) Integration of two-phase solid fluid equations in a catchment model for flashfloods, debris flows and shallow slope failures. Environmental Modelling \& Software 105, 1-16.

Bozzano, F., Lenti, L., Martino, S., Montagna, A. and Paciello, A. (2011) Earthquake triggering of landslides in highly jointed rock masses: Reconstruction of the 1783 Scilla rock avalanche (Italy). Geomorphology 129(3-4), 294-308.

Bray, J. D. and Travasarou, T. (2007) Simplified Procedure for Estimating EarthquakeInduced Deviatoric Slope Displacements. Journal of Geotechnical and Geoenvironmental Engineering 133(4), 381-392.

Brenning, A. (2008) Statistical geocomputing combining R and SAGA: The example of landslide susceptibility analysis with generalized additive models. Hamburger Beiträge zur Physischen Geographie und Landschaftsökologie 19(23-32), 410.

Broeckx, J., Vanmaercke, M., Duchateau, R. and Poesen, J. (2018) A data-based landslide susceptibility map of Africa. Earth-Science Reviews 185, 102-121.

Cama, M., Conoscenti, C., Lombardo, L. and Rotigliano, E. (2016) Exploring relationships between grid cell size and accuracy for debris-flow susceptibility models: a test in the Giampilieri catchment (Sicily, Italy). Environmental Earth Sciences 75(3), 1-21. 
Can, A., Dagdelenler, G., Ercanoglu, M. and Sonmez, H. (2019) Landslide susceptibility mapping at Ovacık-Karabük (Turkey) using different artificial neural network models: comparison of training algorithms. Bulletin of Engineering Geology and the Environment 78(1), 89-102.

Capolongo, D., Refice, A. and Mankelow, J. (2002) Evaluating earthquake-triggered landslide hazard at the basin scale through GIS in the Upper Sele river valley. Surveys in geophysics 23(6), 595-625.

Caprari, P., Della Seta, M., Martino, S., Fantini, A., Fiorucci, M. and Priore, T. (2018) Upgrade of the CEDIT database of earthquake-induced ground effects in Italy. Italian Journal of Engineering Geology and Environment 2, 23-39.

Carminati, E., Lustrino, M., Cuffaro, M. and Doglioni, C. (2010) Tectonics, magmatism and geodynamics of Italy: what we know and what we imagine. Journal of the Virtual Explorer 36(8), 10-3809.

Carrara, A. (1983) Multivariate models for landslide hazard evaluation. Journal of the International Association for Mathematical Geology 15(3), 403-426.

Carrara, A. (1988) Drainage and divide networks derived from high-fidelity digital terrain models. In Quantitative analysis of mineral and energy resources, pp. 581-597. Springer.

Carrara, A., Cardinali, M., Detti, R., Guzzetti, F., Pasqui, V. and Reichenbach, P. (1991) GIS techniques and statistical models in evaluating landslide hazard. Earth Surface Processes and Landforms 16(5), 427-445.

Carrara, A., Cardinali, M., Guzzetti, F. and Reichenbach, P. (1995) GIS technology in mapping landslide hazard. In Geographical information systems in assessing natural hazards, pp. 135-175. Springer.

Castro Camilo, D., Lombardo, L., Mai, P., Dou, J. and Huser, R. (2017) Handling high predictor dimensionality in slope-unit-based landslide susceptibility models through LASSOpenalized Generalized Linear Model. Environmental Modelling and Software 97, 145-156.

Comerci, V., Vittori, E., Blumetti, A., Brustia, E., Di Manna, P., Guerrieri, L., Lucarini, M. and Serva, L. (2015) Environmental effects of the December 28, 1908, Southern CalabriaMessina (Southern Italy) earthquake. Natural Hazards 76(3), 1849-1891.

De Reu, J., Bourgeois, J., Bats, M., Zwertvaegher, A., Gelorini, V., De Smedt, P., Chu, W., Antrop, M., De Maeyer, P., Finke, P. et al. (2013) Application of the topographic position index to heterogeneous landscapes. Geomorphology 186, 39-49.

De Veaux, R. D. and Ungar, L. H. (1994) Multicollinearity: A tale of two nonparametric regressions. In Selecting models from data, pp. 393-402. Springer. 
Delgado, J., García-Tortosa, F. J., Garrido, J., Loffredo, A., López-Casado, C., MartinRojas, I. and Rodríguez-Peces, M. J. (2015) Seismically-induced landslides by a lowmagnitude earthquake: The Mw 4.7 Ossa De Montiel event (central Spain). Engineering Geology 196, 280-285.

Delgado, J., Garrido, J., López-Casado, C., Martino, S. and Peláez, J. (2011) On far field occurrence of seismically induced landslides. Engineering Geology 123(3), 204-213.

DISS-Working-Group (2018) Database of Individual Seismogenic Sources (DISS), Version 3.2.1: A compilation of potential sources for earthquakes larger than M 5.5 in Italy and surrounding areas. http://diss.rm.ingv.it/diss/. Istituto Nazionale di Geofisica e Vulcanologia

Ermini, L., Catani, F. and Casagli, N. (2005) Artificial neural networks applied to landslide susceptibility assessment. geomorphology 66(1-4), 327-343.

Esposito, C., Martino, S., Pallone, F., Martini, G. and Romeo, R. (2016) A methodology for a comprehensive assessment of earthquake-induced landslide hazard, with an application to pilot sites in Central Italy.

Evans, I. S. (1980) An integrated system of terrain analysis and slope mapping. Zeitschrift für Geomorphologie. Supplementband Stuttgart (36), 274-295.

Evans, S. G. and Bent, A. L. (2004) The Las Colinas landslide, Santa Tecla: A highly destructive flowslide triggered by the January 13, 2001, El Salvador earthquake. SPECIAL PAPERS-GEOLOGICAL SOCIETY OF AMERICA pp. 25-38.

Fan, X., Scaringi, G., Korup, O., West, A. J., van Westen, C. J., Tanyas, H., Hovius, N., Hales, T. C., Jibson, R. W., Allstadt, K. E. et al. (2019) Earthquake-Induced Chains of Geologic Hazards: Patterns, Mechanisms, and Impacts. Reviews of Geophysics .

Finke, P. and Montanarella, L. (2001) Basic principals of the manual of procedures (version 1.1) for the georeferenced soil database. Options Méditerranéennes: Série B. Etudes et Recherches 34, 49-65.

Fortunato, C., Martino, S., Prestininzi, A. and Romeo, R. (2012) New release of the italian catalogue of earthquake-induced ground failures (cedit). Italian Journal of Engineering Geology and Environment 2, 63-75.

Frattini, P., Crosta, G. and Carrara, A. (2010) Techniques for evaluating the performance of landslide susceptibility models. Engineering Geology 111(1), 62-72.

Gao, Y., Wang, S., Guan, K., Wolanin, A., You, L., Ju, W. and Zhang, Y. (2020) The Ability of Sun-Induced Chlorophyll Fluorescence From OCO-2 and MODIS-EVI to Monitor Spatial Variations of Soybean and Maize Yields in the Midwestern USA. Remote Sensing $\mathbf{1 2}(7), 1111$. 
Garg, A. and Tai, K. (2012) Comparison of regression analysis, artificial neural network and genetic programming in handling the multicollinearity problem. In 2012 Proceedings of International Conference on Modelling, Identification and Control, pp. 353-358.

Goetz, J., Brenning, A., Petschko, H. and Leopold, P. (2015) Evaluating machine learning and statistical prediction techniques for landslide susceptibility modeling. Computers \& geosciences $\mathbf{8 1}, 1-11$.

Goetz, J. N., Guthrie, R. H. and Brenning, A. (2011) Integrating physical and empirical landslide susceptibility models using generalized additive models. Geomorphology 129(34), 376-386.

Gomez, H. and Kavzoglu, T. (2005) Assessment of shallow landslide susceptibility using artificial neural networks in Jabonosa River Basin, Venezuela. Engineering Geology 78(12), 11-27.

Gorum, T., Fan, X., van Westen, C. J., Huang, R. Q., Xu, Q., Tang, C. and Wang, G. (2011) Distribution pattern of earthquake-induced landslides triggered by the 12 May 2008 Wenchuan earthquake. Geomorphology 133(3-4), 152-167.

Graser, A. (2016) Learning Qgis. Packt Publishing Ltd.

Guisan, A., Theurillat, J. and Zimmermann, N. (1999) SB Weiss, and AD Weiss, 1999: GLM versus CCA spatial modeling of plant species distribution. Plant Ecol 143, 107-122.

Guzzetti, F., Carrara, A., Cardinali, M. and Reichenbach, P. (1999) Landslide hazard evaluation: A review of current techniques and their application in a multi-scale study, central italy. Geomorphology 31(1), 181-216.

Guzzetti, F., Galli, M., Reichenbach, P., Ardizzone, F. and Cardinali, M. (2006) Landslide hazard assessment in the Collazzone area, Umbria, Central Italy. Natural Hazards and Earth System Sciences 6(1), 115-131.

Guzzetti, F., Mondini, A. C., Cardinali, M., Fiorucci, F., Santangelo, M. and Chang, K.-T. (2012) Landslide inventory maps: New tools for an old problem. Earth-Science Reviews 112(1-2), 42-66.

Guzzetti, F., Reichenbach, P., Cardinali, M., Galli, M. and Ardizzone, F. (2005) Probabilistic landslide hazard assessment at the basin scale. Geomorphology 72(1-4), 272-299.

Hassoun, M. H. et al. (1995) Fundamentals of artificial neural networks. MIT press.

Heerdegen, R. G. and Beran, M. A. (1982) Quantifying source areas through land surface curvature and shape. Journal of Hydrology 57(3-4), 359-373. 
Herrera, G., Mateos, R. M., García-Davalillo, J. C., Grandjean, G., Poyiadji, E., Maftei, R., Filipciuc, T.-C., Auflič, M. J., Jež, J., Podolszki, L. et al. (2018) Landslide databases in the Geological Surveys of Europe. Landslides 15(2), 359-379.

Hosmer, D. W. and Lemeshow, S. (2000) Applied Logistic Regression. Second edition. New York: Wiley.

Hsieh, S.-Y. and Lee, C.-T. (2011) Empirical estimation of the Newmark displacement from the Arias intensity and critical acceleration. Engineering Geology 122(1-2), 34-42.

Huang, F., Yin, K., Huang, J., Gui, L. and Wang, P. (2017) Landslide susceptibility mapping based on self-organizing-map network and extreme learning machine. Engineering Geology 223, $11-22$.

Jacek, S. (1997) Landform characterization with geographic information systems. Photogrammetric Engineering \& Remote Sensing 63(2), 183-191.

Jasiewicz, J. and Stepinski, T. F. (2013) Geomorphons - a pattern recognition approach to classification and mapping of landforms. Geomorphology 182, 147-156.

Jenness, J. (2006) Topographic Position Index (tpi_jen. avx) extension for ArcView 3. x, v. 1.3 a. Jenness Enterprises.

Jibson, R. W. (2007) Regression models for estimating coseismic landslide displacement. Engineering geology 91(2-4), 209-218.

Jibson, R. W. and Harp, E. L. (2012) Extraordinary distance limits of landslides triggered by the 2011 mineral, virginia, earthquake. Bulletin of the Seismological Society of America 102(6), 2368-2377.

Jibson, R. W., Harp, E. L. and Michael, J. A. (1998) A method for producing digital probabilistic seismic landslide hazard maps: an example from the Los Angeles, California, area. US Department of the Interior, US Geological Survey.

Jibson, R. W., Harp, E. L. and Michael, J. A. (2000) A method for producing digital probabilistic seismic landslide hazard maps. Engineering Geology 58(3-4), 271-289.

Keefer, D. K. (1984) Landslides caused by earthquakes. Geological Society of America Bulletin 95(4), 406-421.

Keefer, D. K., Wartman, J., Ochoa, C. N., Rodriguez-Marek, A. and Wieczorek, G. F. (2006) Landslides caused by the M 7.6 Tecomán, Mexico earthquake of January 21, 2003. Engineering Geology 86(2-3), 183-197. 
Kirschbaum, D. B., Adler, R., Hong, Y., Hill, S. and Lerner-Lam, A. (2010) A global landslide catalog for hazard applications: method, results, and limitations. Natural Hazards 52(3), $561-575$.

Kirschbaum, D. B., Adler, R., Hong, Y., Kumar, S., Peters-Lidard, C. and Lerner-Lam, A. (2012) Advances in landslide nowcasting: evaluation of a global and regional modeling approach. Environmental Earth Sciences 66(6), 1683-1696.

Korup, O. and Stolle, A. (2014) Landslide prediction from machine learning. Geology today 30(1), 26-33.

Kutner, M. H., Nachtsheim, C. J., Neter, J., Li, W. et al. (2005) Applied linear statistical

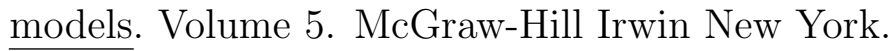

Lagomarsino, D., Tofani, V., Segoni, S., Catani, F. and Casagli, N. (2017) A tool for classification and regression using random forest methodology: Applications to landslide susceptibility mapping and soil thickness modeling. Environmental Modeling \& Assessment 22(3), 201-214.

Lee, S. and Evangelista, D. G. (2006) Earthquake-induced landslide-susceptibility mapping using an artificial neural network. Natural Hazards and Earth System Sciences 6(5), 687-695.

Lenti, L., Martino, S. and Musolino, G. (2017) Considering seismic coefficient distributions within slopes to calculate landslide reactivation probability. Bulletin of engineering geology and the environment 76(4), 1353-1370.

Lima, P., Steger, S., Glade, T., Tilch, N., Schwarz, L. and Kociu, A. (2017) Landslide susceptibility mapping at national scale: a first attempt for Austria. In Workshop on World Landslide Forum, pp. 943-951.

Liu, Z., Shao, J., Xu, W., Chen, H. and Shi, C. (2014) Comparison on landslide nonlinear displacement analysis and prediction with computational intelligence approaches. Landslides 11(5), 889-896.

Lombardo, L., Bakka, H., Tanyas, H., van Westen, C., Mai, P. M. and Huser, R. (2019) Geostatistical modeling to capture seismic-shaking patterns from earthquake-induced landslides. Journal of Geophysical Research: Earth Surface 124(7), 1958-1980.

Lombardo, L., Cama, M., Conoscenti, C., Märker, M. and Rotigliano, E. (2015) Binary logistic regression versus stochastic gradient boosted decision trees in assessing landslide susceptibility for multiple-occurring landslide events: application to the 2009 storm event in Messina (Sicily, southern Italy). Natural Hazards 79(3), 1621-1648. 
Lombardo, L., Cama, M., Märker, M. and Rotigliano, E. (2014) A test of transferability for landslides susceptibility models under extreme climatic events: application to the Messina 2009 disaster. Natural Hazards 74(3), 1951-1989.

Lombardo, L. and Mai, P. M. (2018) Presenting logistic regression-based landslide susceptibility results. Engineering geology 244, 14-24.

Lombardo, L., Opitz, T., Ardizzone, F., Guzzetti, F. and Huser, R. (2020a) Space-time landslide predictive modelling. Earth-Science Reviews p. 103318.

Lombardo, L., Saia, S., Schillaci, C., Mai, P. M. and Huser, R. (2018) Modeling soil organic carbon with Quantile Regression: Dissecting predictors' effects on carbon stocks. Geoderma 318, 148-159.

Lombardo, L. and Tanyas, H. (2020) Chrono-validation of near-real-time landslide susceptibility models via plug-in statistical simulations. Engineering Geology 278, 105818.

Lombardo, L., Tanyas, H. and Nicu, I. C. (2020b) Spatial modeling of multi-hazard threat to cultural heritage sites. Engineering Geology p. 105776.

Lupiano, V., Machado, G. E., Molina, L. P., Crisci, G. M. and Di Gregorio, S. (2018) Simulations of flow-like landslides invading urban areas: a cellular automata approach with SCIDDICA. Natural Computing 17(3), 553-568.

Makdisi, F. I. and Seed, H. B. (1978) Simplified procedure for estimating dam and embankment earthquake-induced deformations. Journal of Geotechnical and Geoenvironmental Engineering 104(Proceeding).

Marjanović, M., Kovačević, M., Bajat, B. and Voženílek, V. (2011) Landslide susceptibility assessment using SVM machine learning algorithm. Engineering Geology 123(3), 225-234.

Martino, S. (2016) Earthquake-induced reactivation of landslides: recent advances and future perspectives. In Earthquakes and Their Impact on Society, pp. 291-322. Springer.

Martino, S. (2017) Earthquake-induced landslides in Italy: from the distribution of effects to the hazard mapping. Italian Journal of Engineering Geology and Environment 1(2017), $53-67$.

Martino, S., Antonielli, B., Bozzano, F., Caprari, P., Discenza, M., Esposito, C., Fiorucci, M., Iannucci, R., Marmoni, G. and Schilirò, L. (2020a) Landslides triggered after the 16 August 2018 M w 5.1 Molise earthquake (Italy) by a combination of intense rainfalls and seismic shaking. Landslides pp. 1-14.

Martino, S., Battaglia, S., Delgado, J., Esposito, C., Martini, G. and Missori, C. (2018) Probabilistic approach to provide scenarios of earthquake-induced slope failures (PARSIFAL) applied to the Alcoy Basin (South Spain). Geosciences 8(2), 57. 
Martino, S., Bozzano, F., Caporossi, P., D’Angiò, D., Della Seta, M., Esposito, C., Fantini, A., Fiorucci, M., Giannini, L., Iannucci, R. et al. (2019) Impact of landslides on transportation routes during the 2016-2017 Central Italy seismic sequence. Landslides 16(6), $1221-1241$.

Martino, S., Bozzano, F., Paolo, C., Danilo, D., Della Seta, M., Carlo, E., Andrea, F., Matteo, F., Giannini, L. M., Roberto, I. et al. (2017) Ground effects triggered by the 24th august 2016, mw 6.0 amatrice (italy) earthquake. surveys and inventoring to update the cedit catalogue. Geografia Fisica e Dinamica Quaternaria 40(1), 77-95.

Martino, S., Caprari, P., Della Seta, M., Esposito, C., Fiorucci, M., Hailemikael, S., Iannucci, R., Marmoni, G., Martini, G., Paciello, A. and Peloso, A. (2020b) Influence of geological complexities on local seismic response in the municipality of Forio (Ischia Island, Italy). Italian Journal of Engineering Geology and Environment p. In press.

Martino, S., Caprari, P., Fiorucci, M. and Marmoni, G. (2020c) The CEDIT Catalogue: from inventorying of earthquake-induced ground effects to analysis of scenario. Mem. Descr. Carta Geol. D'It. 107, 441-450.

Martino, S., Prestininzi, A. and Romeo, R. (2014) Earthquake-induced ground failures in Italy from a reviewed database. Natural Hazards and Earth System Sciences 14(4), 799.

Mazzanti, P. and Bozzano, F. (2011) Revisiting the February 6th 1783 Scilla (Calabria, Italy) landslide and tsunami by numerical simulation. Marine Geophysical Research 32(12), 273-286.

McElroy, T. S. and Jach, A. (2019) Testing collinearity of vector time series. The Econometrics Journal 22(2), 97-116.

Miles, S. and Ho, C. (1999) Rigorous landslide hazard zonation using Newmark's method and stochastic ground motion simulation. Soil Dynamics and Earthquake Engineering 18(4), 305-323.

Nowicki Jessee, M., Hamburger, M., Allstadt, K., Wald, D., Robeson, S., Tanyas, H., Hearne, M. and Thompson, E. (2018) A Global Empirical Model for Near-Real-Time Assessment of Seismically Induced Landslides. Journal of Geophysical Research: Earth Surface 123(8), $1835-1859$.

Ohlmacher, G. C. (2007) Plan curvature and landslide probability in regions dominated by earth flows and earth slides. Engineering Geology 91(2), 117-134.

Patel, V. and Sotiropoulos, F. (1997) Longitudinal curvature effects in turbulent boundary layers. Progress in Aerospace Sciences 33(1-2), 1-70.

Petley, D. (2012) Global patterns of loss of life from landslides. Geology 40(10), 927-930. 
Petley, D., Dunning, S., Rosser, N. and Hungr, O. (2005) The analysis of global landslide risk through the creation of a database of worldwide landslide fatalities. Landslide risk management. Balkema, Amsterdam pp. 367-374.

Porfido, S., Esposito, E., Vittori, E., Tranfaglia, G., Guarrieri, L. and Pece, R. (2007) Seismically induced ground effects of the 1805, 1930 and 1980 earthquakes in the southern apennines (italy. Boll. Soc. Geol. It.(Ital. J. Geosci.) 126, 333--346.

Prestininzi, A. and Romeo, R. (2000) Earthquake-induced ground failures in Italy. Engineering Geology 58(3-4), 387-397.

Putin, E., Mamoshina, P., Aliper, A., Korzinkin, M., Moskalev, A., Kolosov, A., Ostrovskiy, A., Cantor, C., Vijg, J. and Zhavoronkov, A. (2016) Deep biomarkers of human aging: application of deep neural networks to biomarker development. Aging (Albany NY) 8(5), 1021.

Rahmati, O., Kornejady, A., Samadi, M., Deo, R. C., Conoscenti, C., Lombardo, L., Dayal, K., Taghizadeh-Mehrjardi, R., Pourghasemi, H. R., Kumar, S. et al. (2019) PMT: New analytical framework for automated evaluation of geo-environmental modelling approaches. Science of the total environment 664, 296-311.

Rathje, E. M., Abrahamson, N. A. and Bray, J. D. (1998) Simplified frequency content estimates of earthquake ground motions. Journal of geotechnical and geoenvironmental engineering 124(2), 150-159.

Rathje, E. M. and Bray, J. D. (2000) Nonlinear Coupled Seismic Sliding Analysis of Earth Structures. Journal of Geotechnical and Geoenvironmental Engineering 126(11), 10021014.

Reichenbach, P., Rossi, M., Malamud, B. D., Mihir, M. and Guzzetti, F. (2018) A review of statistically-based landslide susceptibility models. Earth-Science Reviews 180, 60-91.

Riley, S. J., DeGloria, S. D. and Elliot, R. (1999) Index that quantifies topographic heterogeneity. intermountain Journal of sciences 5(1-4), 23-27.

Rodriguez, C., Bommer, J. and Chandler, R. (1999) Earthquake-induced landslides: 19801997. Soil Dynamics and Earthquake Engineering 18(5), 325-346.

Romeo, R. (2000) Seismically induced landslide displacements: a predictive model. Engineering Geology 58(3-4), 337-351.

Rossi, M., Guzzetti, F., Reichenbach, P., Mondini, A. C. and Peruccacci, S. (2010) Optimal landslide susceptibility zonation based on multiple forecasts. Geomorphology 114(3), 129142. 
Rossi, M. and Reichenbach, P. (2016) LAND-SE: a software for statistically based landslide susceptibility zonation, version 1.0. Geoscientific Model Development 9(10), 3533.

Sabetta, F. and Pugliese, A. (1987) Attenuation of peak horizontal acceleration and velocity from italian strong-motion records. Bulletin of the Seismological Society of America 77(5), 1491-1513.

Sassa, K. (1996) Prediction of earthquake induced landslides. In Landslides, pp. 115-132.

Saygili, G. and Rathje, E. M. (2009) Probabilistically based seismic landslide hazard maps: an application in Southern California. Engineering Geology 109(3-4), 183-194.

Schlögel, R., Marchesini, I., Alvioli, M., Reichenbach, P., Rossi, M. and Malet, J.-P. (2018) Optimizing landslide susceptibility zonation: Effects of DEM spatial resolution and slope unit delineation on logistic regression models. Geomorphology 301, 10-20.

Sepúlveda, S. A., Murphy, W., Jibson, R. W. and Petley, D. N. (2005) Seismically induced rock slope failures resulting from topographic amplification of strong ground motions: The case of Pacoima Canyon, California. Engineering geology 80(3-4), 336-348.

Shao, X., Xu, C., Ma, S. and Zhou, Q. (2019) Effects of Seismogenic Faults on the Predictive Mapping of Probability to Earthquake-Triggered Landslides. ISPRS International Journal of Geo-Information 8(8), 328.

Shrestha, S. and Kang, T.-S. (2019) Assessment of seismically-induced landslide susceptibility after the 2015 Gorkha earthquake, Nepal. Bulletin of Engineering Geology and the Environment 78(3), 1829-1842.

Sieberg, A. H. (1930) Geologie der erdbeben.

Song, Y., Gong, J., Gao, S., Wang, D., Cui, T., Li, Y. and Wei, B. (2012) Susceptibility assessment of earthquake-induced landslides using Bayesian network: A case study in Beichuan, China. Computers \& Geosciences 42, 189-199.

Steger, S., Schmaltz, E. and Glade, T. (2020) The (f) utility to account for pre-failure topography in data-driven landslide susceptibility modelling. Geomorphology 354, 107041.

Taalab, K., Cheng, T. and Zhang, Y. (2018) Mapping landslide susceptibility and types using Random Forest. Big Earth Data 2(2), 159-178.

Tacchia, D., Masella, G., Pannuti, V. and Vitale, V. (2005) La nuova Carta Geologica d'Italia scala 1: 1,000,000. In Atti della 9 Conferenza Nazionale ASITA, volume 15, p. 18.

Tang, C., Zhu, J., Qi, X. and Ding, J. (2011) Landslides induced by the Wenchuan earthquake and the subsequent strong rainfall event: A case study in the Beichuan area of China. Engineering Geology 122(1-2), 22-33. 
Tanyaş, H., van Westen, C., Allstadt, K., Nowicki, A. J. M., Görüm, T., Jibson, R., Godt, J., Sato, H., Schmitt, R., Marc, O. and Hovius, N. (2017) Presentation and Analysis of a Worldwide Database of Earthquake-Induced Landslide Inventories. Journal of Geophysical Research: Earth Surface 122(10), 1991-2015.

Tanyaş, H. and Lombardo, L. (2019) Variation in landslide-affected area under the control of ground motion and topography. Engineering Geology 260, 105229.

Tanyaş, H. and Lombardo, L. (2020) Completeness Index for Earthquake-Induced Landslide Inventories. Engineering geology 264, 105331.

Tanyaş, H., Rossi, M., Alvioli, M., van Westen, C. J. and Marchesini, I. (2019) A global slope unit-based method for the near real-time prediction of earthquake-induced landslides. Geomorphology 327, 126-146.

Tian, Y., Xu, C., Hong, H., Zhou, Q. and Wang, D. (2019) Mapping earthquake-triggered landslide susceptibility by use of artificial neural network (ANN) models: an example of the 2013 Minxian (China) Mw 5.9 event. Geomatics, Natural Hazards and Risk 10(1), $1-25$.

Tosatti, G., Castaldini, D., Barbieri, M., D’Amato Avanzi, G., Giannecchini, R., Mandrone, G., Pellegrini, M., Perego, S., Puccinelli, A., Romeo, R. W. et al. (2008) Additional causes of seismical related landslides in the Northern Apennines, Italy. Revista de geomorfologie 10, $5-21$.

Trigila, A., Frattini, P., Casagli, N., Catani, F., Crosta, G., Esposito, C., Iadanza, C., Lagomarsino, D., Mugnozza, G. S., Segoni, S. et al. (2013) Landslide susceptibility mapping at national scale: the Italian case study. In Landslide science and practice, pp. 287-295. Springer.

Umar, Z., Pradhan, B., Ahmad, A., Jebur, M. N. and Tehrany, M. S. (2014) Earthquake induced landslide susceptibility mapping using an integrated ensemble frequency ratio and logistic regression models in West Sumatera Province, Indonesia. Catena 118, 124-135.

Van Westen, C. (2002) Use of weights of evidence modeling for landslide susceptibility mapping. International Institute for Geoinformation Science and Earth Observation: Enschede, The Netherlands p. 21.

Van Westen, C., Van Asch, T. W. and Soeters, R. (2006) Landslide hazard and risk zonation - why is it still so difficult? Bulletin of Engineering geology and the Environment 65(2), 167-184.

Varnes and the IAEG Commission on Landslides and Other Mass-Movements (1984) Landslide hazard zonation: A review of principles and practice. Natural Hazards, Series. Paris: United Nations Economic, Scientific and cultural organization. UNESCO 3, 63. 
Wang, K.-L. and Lin, M.-L. (2010) Development of shallow seismic landslide potential map based on Newmark's displacement: the case study of Chi-Chi earthquake, Taiwan. Environmental Earth Sciences 60(4), 775-785.

Wang, Y., Fang, Z. and Hong, H. (2019) Comparison of convolutional neural networks for landslide susceptibility mapping in Yanshan County, China. Science of the total environment 666, 975-993.

Wood, J. (1996) The geomorphological characterisation of digital elevation models. Ph.D. thesis, University of Leicester.

Youd, T. L. and Hoose, S. N. (1978) Historic ground failures in northern California triggered by earthquakes. Volume 993. US Govt. Print. Off.

Zevenbergen, L. W. and Thorne, C. R. (1987) Quantitative analysis of land surface topography. Earth surface processes and landforms 12(1), 47-56.

Zhou, C., Yin, K., Cao, Y. and Ahmed, B. (2016) Application of time series analysis and PSO-SVM model in predicting the Bazimen landslide in the Three Gorges Reservoir, China. Engineering geology 204, 108-120.

Zhou, C., Yin, K., Cao, Y., Ahmed, B., Li, Y., Catani, F. and Pourghasemi, H. R. (2018) Landslide susceptibility modeling applying machine learning methods: A case study from Longju in the Three Gorges Reservoir area, China. Computers \& Geosciences 112, 23-37.

Zhou, S. and Fang, L. (2015) Support vector machine modeling of earthquake-induced landslides susceptibility in central part of Sichuan province, China. Geoenvironmental disasters $2(1), 2$.

Zhu, X., Xu, Q., Tang, M., Nie, W., Ma, S. and Xu, Z. (2017) Comparison of two optimized machine learning models for predicting displacement of rainfall-induced landslide: A case study in Sichuan Province, China. Engineering geology 218, 213-222. 